\title{
Towards a Framework for Process Mapping and Performance Measurement in Construction Supply Chains
}

\author{
Micael Thunberg
}

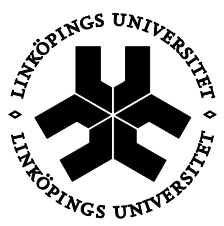

\section{Linköping University}

Department of Science and Technology

Linköping University

SE-601 74 Norrköping, Sweden

Norrköping 2013 
Towards a Framework for Process Mapping and Performance Measurement in Construction Supply Chains

(CMicael Thunberg, 2013

Cover Design: Micael Thunberg

Published articles have been reprinted with the permission of the copyright holder.

Printed in Sweden by LiU-Tryck, Linköping, Sweden, 2013

ISBN: 978-91-7519-462-2

ISSN: 0280-7971

Thesis No. 1631

LIU-TEK-LIC-2013:65 


\section{Abstract}

The purpose with this study is to develop a framework for process mapping and performance measurement in construction supply chains. This is done as current literature suggest that many of the problems that cause the cost- and time overruns in construction can be mitigated by implementing supply chain management (SCM) principles. For example, temporary organisations, fragmentation, etc. can affect the time and cost as work and information among members easily are delayed and even distorted. It is also recognised by many authors that planning the construction work and logistics often are tainted with synchronisation and coordination problems between supply chain members. It is deemed necessary with a framework ${ }^{1}$ for mapping logistic activities and measuring supply chain performance. Up until now, there exists no framework for mapping the whole construction supply chain and measuring its performance, that encompasses the whole chain from raw material to the finished building.

As stated above, the purpose with this thesis is to develop such a framework. In order to do so an existing framework is used as a basis, the Supply Chain Operations Reference (SCOR) model. The SCOR model consists of five process groups (Plan, Source, Make, Deliver, and Return) hierarchically structured in three levels and some 500 predefined performance metrics. This framework is proven fruitful in other industries but it is also proven by other authors in the field suitable as a basis for a construction adapted version. Other frameworks do exist, but none of these are as comprehensive as the SCOR model. Resent research also suggests that the SCOR model is possible to adjust to unique industry settings. It is identified in this study that the SCOR model has to be adapted to the characteristics of the construction industry. Therefore, the framework presented in this thesis is developed via adaption of the SCOR model to the characteristics of the construction industry. In doing so, a total of four research objectives corresponding to the process groups in the SCOR model are considered for adapting the SCOR model. The Return process, however, is not included in this thesis.

Objective 1. Adapt the SCOR model's Deliver process to the characteristics of the construction industry.

Objective 2. Adapt the SCOR model's Source processes to the characteristics of the construction industry.

\footnotetext{
${ }^{1}$ The terms framework and model are in this thesis used interchangeably for describing a set of identified actions that can be proceed for achieving a certain purpose
} 
Objective 3. Adapt the SCOR model's Make processes to the characteristics of the construction industry.

Objective 4. Adapt the SCOR model's Plan processes to the characteristics of the construction industry.

The main method utilised in the study is case study research. The results are derived from a total of three case studies. The SCOR model is applied to the cases as it is. Through observing how suitable the framework is for the industry the four aforementioned objectives are addressed. Except from direct observations (with time measurements), other data gathering methods utilised are questionnaires and interviews.

The adapted version of the SCOR model is entitled the Builder's SCOR model (BSCOR). Findings from the studies indicate that necessary changes to the SCOR model concerns how the material flow in the processes are separated. The SCOR model suggests separating materials based on type of end product (e.g. Make-to-Stock - MTS, Make-toOrder - MTO, or Engineer-to-Order - ETO character). In the BSCOR model, the flow of materials are separated based on who orders them (the main contractor or any of the subcontractors), rather than type of material. The BSCOR model also suggests how the planning process should be organised in order to overcome coordination issues. Finally, one measurement included in the BSCOR model is to keep track of whether an incoming delivery of construction materials is notified in time. An order is not perfectly delivered if it is not notified in time.

One managerial contribution with the study is a framework for mapping supply chain activities and measuring supply chain performance. The framework also offers the ability to measure how the supply chain of a company performs compared to other companies' supply chains. The study contributes to the academia as it fills the gap of a lack in frameworks suitable for mapping and measuring construction logistics. It also contributes in reporting on the current logistics status in the construction industry. 


\section{Populärvetenskaplig sammanfattning}

Tänk om det såg ut så här i byggbranschen... "Projekteringen är klar och upphandlingen av nya material och nya leverantörer skall precis börja. Byggarens logistikverktyg BSCOR används för att dra lärdomar från förra projektet. Leverantören av fönster klarade av att leverera $67 \%$ i rätt tid, till rätt plats, $i$ rätt kvantitet och med rätt dokumentation. Skall vi köra på samma leverantör igen eller skall vi byta? Genom att separera underentreprenörernas leveranser från våra egna, lyckades vi hålla nere lagernivåerna på ett minimum. Vi måste göra leveransplaner med underentreprenörerna även denna gång för att lyckas synkronisera leveranserna. Mätningar visar även att aviseringen från leverantörerna brister. Här måste vi återigen kommunicera med leverantören vikten av att avisera leveranser i tid. Med alla mätningar från byggarens logistikverktyg har vi för första gången data, svart på vitt, om hur leverantörer sköter sina åtaganden, hur lång tid vi tar på oss för att lossa gods och vad det är vi egentligen gör när det kommer material till vår byggarbetsplats."

I min forskning tar jag fram ett verktyg, kallat Builder's Supply Chain Operations Reference model, BSCOR, för att tidigt hitta problem och för att utvärdera hur de påverkar byggprojektet i sin helhet. Stor vikt läggs på att hitta problem i det som kallas försörjningskedjan ${ }^{1}$ till byggarbetsplatsen, se figuren nedan. Genom att problemen kan hittas och åtgärdas tidigt kan kostnaderna hållas nere. Minskade kostnader leder i sin tur till att man kan bygga billigare bostäder. Att entreprenörerna nu kan få svart på vitt hur väl logistiken fungerar innebär även att de vet var någonstans man behöver förbättra sig. Kanske kan snabbare och mer pålitliga leveranser av exempelvis gipsskivor leda till mindre material som är i vägen på byggarbetsplatsen? Vilket i sin tur kanske leder till bättre framkomlighet och därmed till mer effektiva hantverkare?

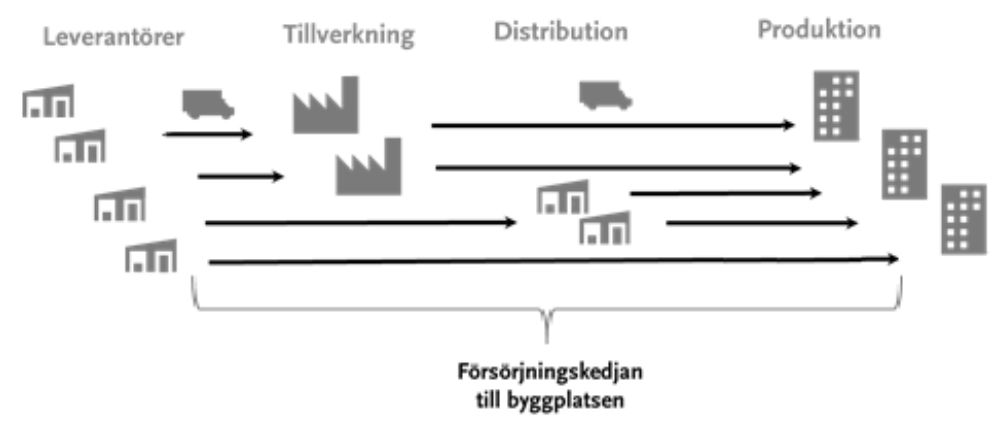

\footnotetext{
${ }^{1}$ Ett nätverk av företag och operationer som utförs för att bearbeta råmaterial till en slutprodukt och transportera slutprodukten till en kund.
} 
Det som skiljer min forskning från tidigare utförd forskning är vikten av helhetstänk. Tidigare forskning har gått ut på att fokusera på kvaliteten på bostaden utifrån kundens perspektiv. Detta är nog så viktigt, men inte mindre viktigt är hur bristande kvalitet från leverantörernas sida påverkar kvaliteten på bostaden. Om en leverans av exempelvis gipsskivor kommer försent kan det försena hela projektet. Om dessutom gipsskivorna är av fel typ kan detta påverka kvaliteten på bostaden. Det är alltså viktigt att ha ett helhetsperspektiv.

Verktyget har tagits fram tillsammans med personal på ett antal byggarbetsplatser. Deras expertis om byggbranschen och min kunskap om logistik har resulterat $\mathrm{i}$ ett logistikverktyg anpassat för byggbranschen. Ett verktyg som inte funnits tidigare. 


\section{Foreword}

Before I started my PhD-studies I was not sure if I wanted to. "Will I make it?" "Do I want to be a PhD student?" But at the same time as I questioned a presumptive future carrier as a PhD-student I knew I wanted. I love to learn new things and question why things are as they are. So I knew I would enjoy being a PhD-student, and I have not regretted it (so far).

There are so many people that I wish to thank in supporting me while writing this thesis and while working with my project. First of all, I wish to thank my two supervisors Martin Rudberg and Fredrik Persson for always encouraging, inspiring, and (sometimes) pushing me to always do my best. Without you two, I would not be where I am today. Thanks! I also want to thank my colleagues at the Department of Science and Technology especially Magnus Lindskog, Martin Heljedal, Henric Jonsson, and Andreas Ekeskär. With the help from you guys, by reading and commenting on the papers, the thesis has improved in quality, a lot. Furthermore, your senses of humour and open minds have stimulated the work with producing this thesis. Other people I wish to thank are Maria Johansson, Glenn Gyllin, Lars Gutwasser, Jonas Thörnqvist, and Jesper Strandberg.

Finally, the ones that I cannot forget are my dearest friends and family. You have all supported me when I have felt anxious about my thesis but also shared the joy over my progress. 


\section{Acknowledgement}

The author is grateful for the work Robert Javalds, Henrik Lokander, Robin Johansson, Glenn Gyllin, and Maria Johansson have contributed with in order to develop the BSCOR framework. The funding for this work comes from Brains \& Bricks - a researchcollaboration between Linköping University, the municipality of Katrineholm, and the construction company Peab, see also www.liu.se/forskning/b2. 


\section{Thesis Outline}

This thesis is of a compilation character (thesis by publication) comprising four articles; one published in an ISI-classified journal, two published in conference proceedings, and one working paper. The thesis is titled Towards a framework for process mapping and performance measurement in construction supply chains as it ought to develop a framework that could be used for mapping and measuring construction supply chains. The introductory chapters in this thesis set out to describe the background to why the work is deemed necessary, together with the purpose and research objectives. It will also guide the reader in the current literature and what each paper in the thesis concerns. Finally, the introductory chapters will also describe the work with compiling and present the final framework. It will also pinpoint the contributions and present ideas on future work. Listed below are those four articles that, together with the introductory chapters, constitute this thesis.

\section{Paper 1}

Thunberg, M. and Persson, F. (2013). "Using the Scor Model's Performance Measurements to Improve Construction Logistics." Production Planning and Control (Online). DOI: 10.1080/09537287.2013.808836

\section{Paper 2}

Persson, F. and Thunberg, M. (2012). "Adapting the SCOR Model to the Construction Industry Settings”. In: Töyli, J., Johansson, L., Lorentz, H., Ojala, L. \& Laari, S. (Eds.), 24th NOFOMA 2012, 7-8th of June 2012 Turku, Finland.

\section{Paper 3}

Thunberg, M. and Persson, F. (2013). "Adapting the SCOR Make Process to the Construction Industry Settings”. Working Paper Available at: www.bscor.com.

\section{Paper 4}

Thunberg, M., Persson, F. and Rudberg, M. (2013). "Coordinated Supply Chain Planning in Construction”. In: Klakegg, O. J., Kjølle, K. H., Mehaug, C. G., Olsson, N. O. E., Shiferaw, A. T. \& Woods, R. (Eds.), 7th Nordic Conference on Construction Economics and Organisation, 12-14th of June 2013 Trondheim, Norway. 


\section{Table of Contents}

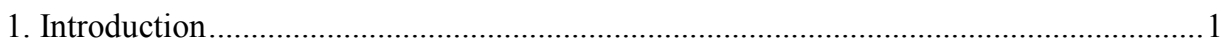

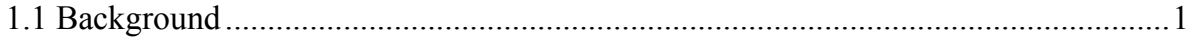

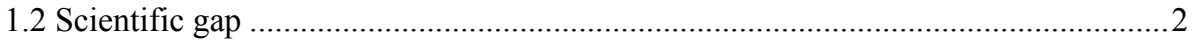

1.3 Purpose and Contribution to the Research Field........................................................ 2

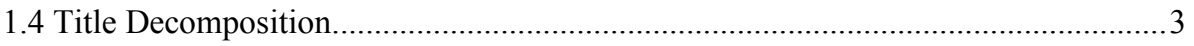

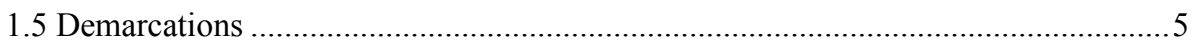

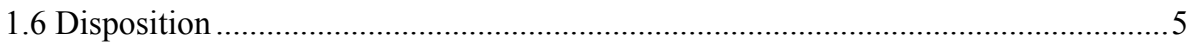

2. Supply Chain Management and Construction ......................................................... 7

2.1 Supply Chain Management and Logistics ............................................................ 7

2.1.1 Supply Chain Management........................................................................... 7

2.1.2 Effects of Implementing SCM and Potential Barriers .................................... 9

2.1.3 Performance Measurement in Supply Chains .................................................. 10

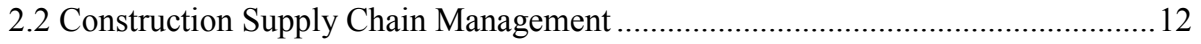

2.2.1 The Perspective on SCM as Logistic Tools ..................................................... 13

2.2.2 SCM as a Means to Integrate Members ......................................................... 13

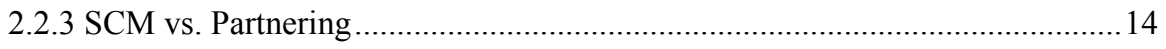

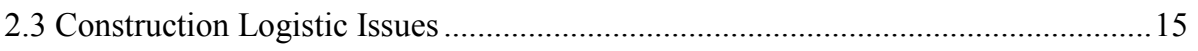

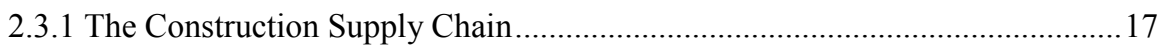

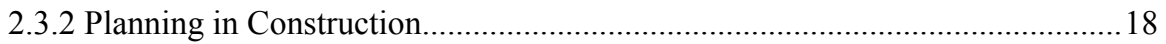

2.4 Performance Measurement in Construction Supply Chains …...............................2.

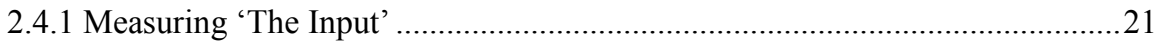

2.4.2 Measuring 'The Process' and 'The Output' ....................................................22

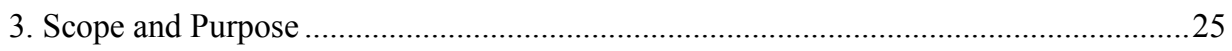

3.1 Condense the Literature to Define the Scope and Purpose .....................................25

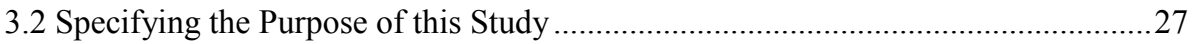

3.3 The Supply Chain Operations Reference Model .................................................28

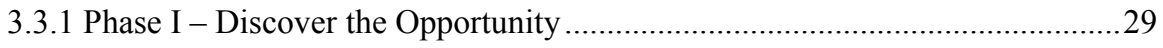

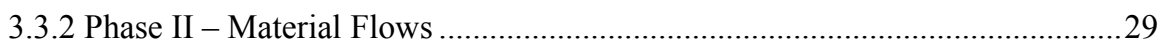


3.3.3 Phase III - Analyse the Supply Chains …..................................................... 31

3.3.4 Phase IV - Work and Information Flows ...........................................................33

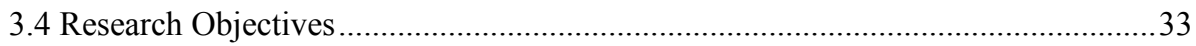

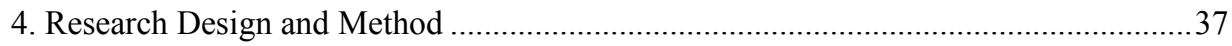

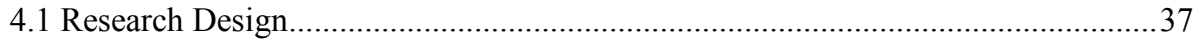

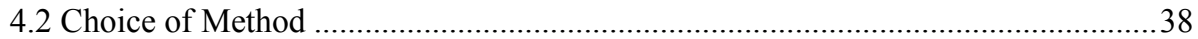

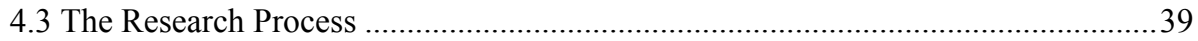

4.3.1 Paper 1 - Assessing Construction Logistics Performance.................................40

4.3.2 Paper 2 - The First Step in Creating the BSCOR Model .................................41

4.3.3 Paper 3 - Developing the Build Process .......................................................... 41

4.3.4 Paper 4 - Coordinated Supply Chain Planning.................................................42

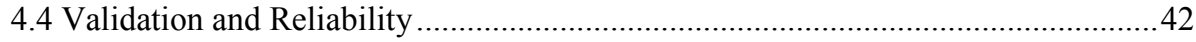

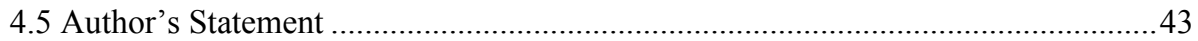

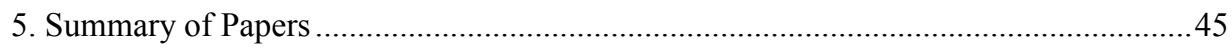

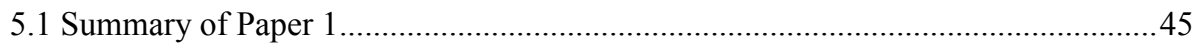

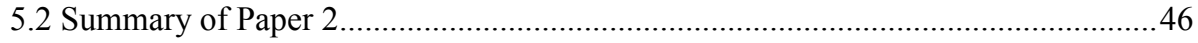

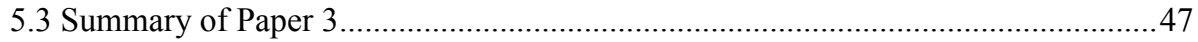

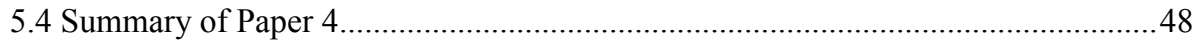

6. Developing a Construction Supply Chain Framework ...............................................51

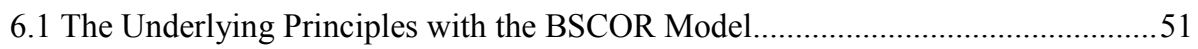

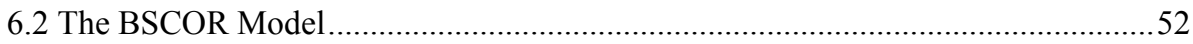

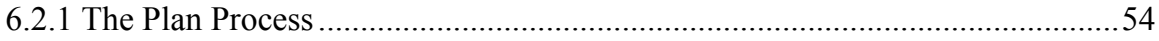

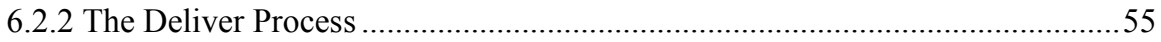

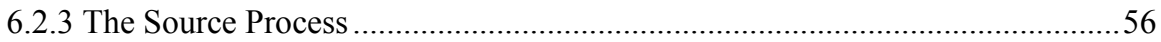

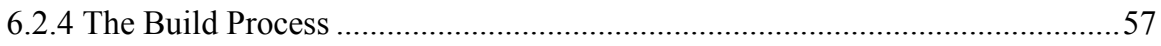

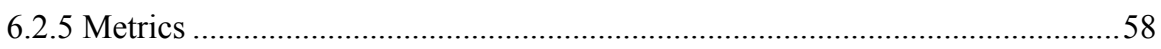

6.3 Discussion on Implementation of the BSCOR Model .........................................59

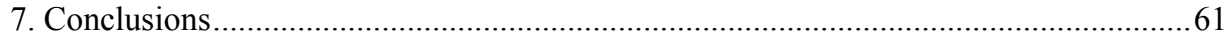

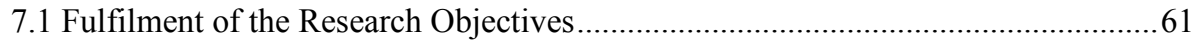

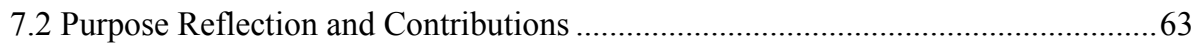

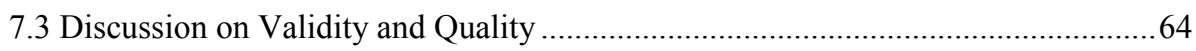

7.4 Suggestions of Further Development of the BSCOR Model ..................................65

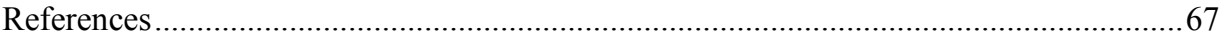


Paper 1 - Using the SCOR model's performance measurements to improve construction logistics

Paper 2 - Adapting the SCOR model to the construction industry settings

Paper 3 - Adapting the SCOR make process to the construction industry settings

Paper 4 - Coordinated supply chain planning in construction 


\section{Introduction}

"Not everything that counts can be counted, and not everything that can be counted counts."

William Bruce Cameron (1963)

It is a common belief in the construction industry that putting greater emphasis on managing the whole supply chain, from raw materials to the end-customer, can affect cost, time, and quality positively. However, managing the supply chain is still in its infancy in the construction industry and it is not agreed upon how to implement supply chain management principles. This thesis won't offer a roadmap for how to implement supply chain management in the construction industry. What it will offer is a structured framework for process mapping and performance measurement in construction supply chains. With this framework, practitioners can keep track on what effect different supply chain solutions might have.

\subsection{Background}

Many researchers have for a long time pointed out potential problems in the construction industry. These problems can result in an increase in the construction cost and a decrease in the construction productivity, demonstrated by Vrijhoef and Koskela (2000). Laufer and Tucker (1987) and Gidado (2004) stress the deficiencies in planning as a potential cause to time and cost overruns. In general terms, they blame the cost-increase and production problems on a lack of understanding the role of planning. Other authors such as Latham (1994), Egan (1998), and Bankvall et al. (2010) conclude that the current situation stems from an inadequate way of managing suppliers and subcontractors. If the planning problems, the inadequate management of supply chains, and use of temporary organisations are not managed, their effect can, according to Fearne and Fowler (2006), not only affect the costs and productivity but also affect the construction project performance in total (like quality). Section 2.3 Construction Logistic Issues describes these problems in more detail.

In this thesis, the problems (planning deficiencies and supply chain management issues) are not seen as two isolated areas that should be mitigated solitarily. Instead, the problems are dealt with in conjunction. As Cheng et al. (2010) emphasize in their report, many of the existing construction problems (such as planning problems, temporary supply chains, bad performance, etc.) can be eased if greater attention is put on developing a framework 
for mapping, measuring, and continuously learning from each construction project. Authors such as Bassioni et al. (2005) and Wegelius-Lehtonen (2001) share this view, that a framework can be helpful in order to reap the benefits from better managed supply chains. The problems with the few available current frameworks is that they tend to focus on one part of the chain and not on the complete chain from raw material to finished house (e.g. Wegelius-Lehtonen 2001), or that they are entirely based on existing frameworks developed for other industries without adjusting them to the construction context (e.g. Cheng et al. 2010).

\subsection{Scientific gap}

Pan et al. (2010) highlight that the number of frameworks offering a structured tool comprehending the whole supply chain (from raw material to the end-customer) for mapping and measuring the supply chain in construction is scarce. Cheng et al. (2010) elaborate on the idea to implement such a framework. They use an already existing framework as a basis but do not consider the aspect of contextual differences between the manufacturing industry and construction industry, which is of great importance according to Green et al. (2005). Wegelius-Lehtonen and Pahkala (1998) and Wegelius-Lehtonen (2001) also develop a framework for measuring supply chain performance but focus merely on the material delivery part of the supply chain and lack e.g. in not considering on-site logistics.

Overall, it is quite common that focus is put on the contractor-client perspective and not on the supplier-contractor perspective (Dainty et al. 2001, Bygballe et al. 2010, Vidalakis et al. 2011). The problem then is that many problems that arise early in the supply chain are missed (Vrijhoef and Koskela 2000, Wickramatillake et al. 2007). If also suppliers are considered, it is easier to see how supplier problems affect project and product performance (Pan et al. 2010). Therefore, a framework for measuring performance from suppliers to customers is important, as many problems do arise early in the supply chain and cause more severe problems on-site (Vrijhoef and Koskela 2000). A framework for mapping and measuring logistic activities from suppliers to the end-customer, developed exclusively for the construction industry, is lacking today. The scientific gap can therefore be summarised as a lack of supply chain frameworks for mapping and measuring logistic activities and performance in the construction supply chain.

\subsection{Purpose and Contribution to the Research Field}

The purpose is to develop a framework for process mapping and performance measurement in construction supply chains. The idea is that the purpose will be specified after the literature review. After reading the literature review in section 2 the reason for why phrasing the purpose as done above will be much clearer. Therefore, a thoroughly review of the purpose is also presented in section 3 .

The anticipated practical implication of this research is a structured framework for process mapping and performance measurement in construction supply chains. There is 
today a common belief that performance in construction is staggering or even deteriorates. With this framework, construction companies are able to, in a systematic manner, map construction supply chain activities (to see what is happening) and measure the performance of the chain. With a systematic evaluation system, trends in performance directions can be identified.

For the research field, the introduction of this framework fills the gap with a lack of frameworks for mapping and measuring logistic activities from raw material to the endcustomer. The thesis also contributes to the field via a thorough presentation of common construction problems and how a standardised framework can aid in overcoming these problems.

\subsection{Title Decomposition}

This thesis is titled "Towards a framework for process mapping and performance measurement in construction supply chains". In this thesis, 'towards' means that the proposed framework is of a tentative nature. The suggested contents of the framework should not be seen as written in stone. Suggested contents are based on the current perception of the construction industry. If the industry 'changes', or the perception of what should be included in the framework, the content of the framework should be updated.

The word 'framework' is a more difficult word to define. As Soni and Kodali (2013) elaborate on, there is no coherence in the literature on what a framework is and what separates it from a model. In this thesis, the terms model and framework are used synonymously for identifying what actions can proceed for a certain purpose (Soni and Kodali 2013). However, the meaning of a model is to guide entities (such as companies) to a better practice (like best practice). A model therefore contains a normative nature. A framework, on the other-hand, is more of a descriptive nature as it contains 'tools' for seeking solutions to existing problems.

In order to define what 'process mapping' is we need to know what a process is and what the concept of mapping is. A process is according to CSCMP (2013):

"A series of time-based activities that are linked to complete a specific output." (CSCMP 2013)

A process is therefore an aggregation of a number of activities to produce a certain goal. A rather formal definition of mapping proposed by Farlex (2013) is:

"[Mapping is a] rule of correspondence established between sets that associates each element of a set with an element in the same or another set." (Farlex 2013)

It means e.g. to find and link activities to one process. Therefore 'process mapping' is about identify and define each process and what activities each process contains. 
Answering what 'performance' and 'performance measurement' is (especially the former one) is the million dollar question and requires a lot of courage to tackle. One definition pronounced by Business Dictionary (2013) is:

"The accomplishment of a given task measured against present known standards of accuracy, completeness, cost, and speed. In a contract, performance is deemed to be the fulfilment of an obligation, in a manner that releases the performer from all liabilities under the contract." (BusinessDictionary 2013)

They explicitly mean that both financial and non-financial aspects should be considered. Bassioni et al. (2005) report on a perception in construction that performance means project performance regarding time, cost, and quality. Performance could also mean a company's ability to achieve delivery reliability and speed responsiveness or customer satisfaction. 'Performance measurement' therefore includes the systematic measurement to see how well the company performs in a certain aspect.

The final concept to clarify is 'construction supply chain'. Stevens (1986) defines an 'ordinary' supply chain as the flow of material from supplier to a customer with a series of activities for planning, coordinating, and controlling the flows. This is also applicable for a construction supply chain. However, a construction supply is more complex as entities such as consultants and sub-trades are included (Cox and Ireland 2002, O'Brien et al. 2002). Figure 1 below partly depicts the complexity of a construction supply chain. It consists of three major flows: (1) a material chain, (2) a labour chain, and (3) a resource chain. Add to this the complexity of who the customer is (the client or the end-user) and how information input from consultants, architects, designers, etc. should be treated. Yet another complicating factor is that the factory is built at the same time as the end product plus the changing layouts on-site. Hence, a 'construction supply chain' resembles an 'ordinary' supply chain in many senses but cannot be managed in the same way due to the discrepancies discussed above (Akintoye et al. 2000).

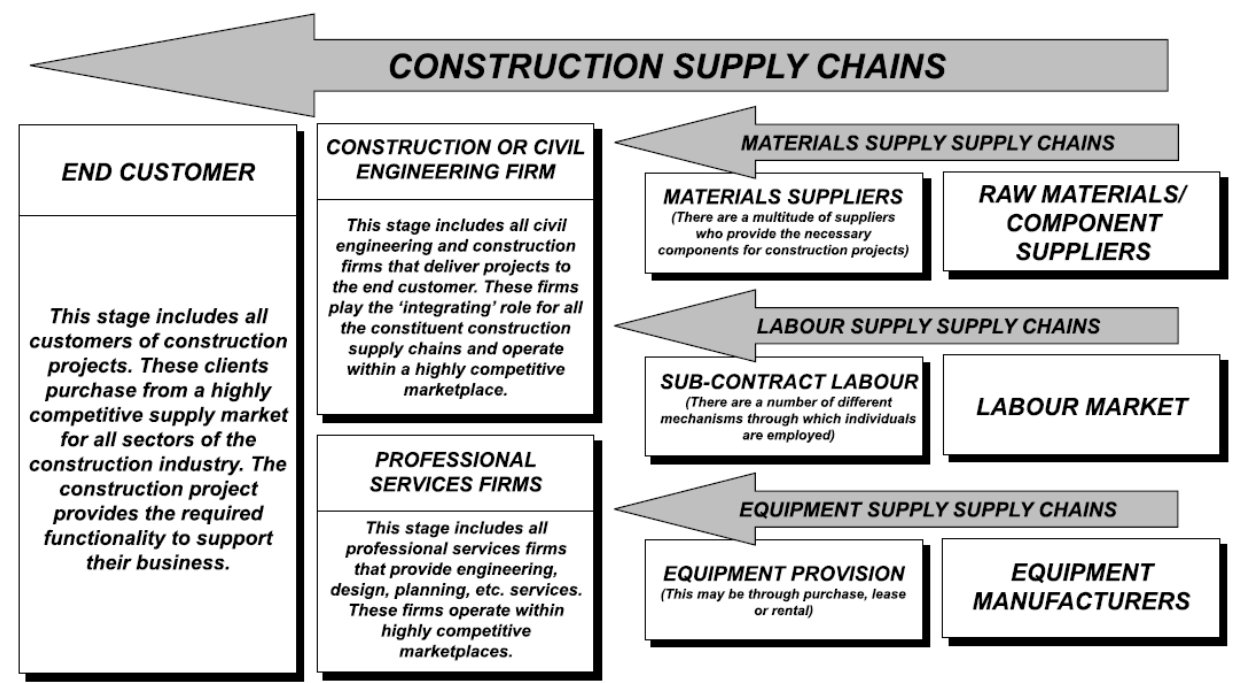

Figure 1 : The structure of a construction supply chain, source Cox and Ireland (2002). 


\subsection{Demarcations}

The overall purpose with this thesis is to develop a framework for process mapping and performance measurement in construction supply chains; it does not suggest how to implement the framework. This matter, and which member in the supply chain that should lead the work with implementing it, is left for future studies. The overall focus in the thesis is on three parts in a construction supply chain. (1) The interface between the suppliers and the construction site, often called the 'deliver' and 'source' processes. (2) The planning process. (3) The building process. The focus is chosen as these three 'areas' are the ones that include most logistics activities and have a great impact on other processes. Therefore, the handover process and the return process are left out in this study. This might raise some questions about if the thesis actually can fulfil the purpose if these two areas are left out. This is thoroughly discussed in section 7, but the short answer is 'yes' as these are not entirely left out, they are just not 'considered' in this thesis. Lastly, each part of the framework has been developed in different case studies. Findings from the precedent studies have been validated during the succeeding studies. Yet, a test case, where the whole framework as such is tested and validated, is necessary and has not been performed in this project.

\subsection{Disposition}

The purpose with this introductory chapter was to give a grasp overview of what to expect from this thesis (develop a framework for process mapping and performance measurement in construction supply chains). It also sets the boundaries, what not to study (e.g. how to implement SCM principles). However, a lot of information presented in this introductory chapter might not be fully clear until reading section 2 and 3 . In section 2, a thorough discussion on what supply chain management (SCM) is and examples of supply chain performance measurements systems are given. This section also provides an examination of common construction problems facing the industry plus how the construction industry perceives SCM. After reading section 2, the reader should have got a clearer idea of why the purpose is phrased as it is in 1.3 Purpose and Contribution to the Research Field. However, these reasons are not literally expressed in section 2, this is done in section 3. In section 3 the 'what' and 'why' questions are further developed. This section takes the overall purpose presented in section 1.3 and decomposes it into a more distinct purpose and achievable objectives. Section 3 starts with extracting crucial information from section 2 and connects the information to a discussion about frameworks. After reading section 3, the reader should have a clear view on 'what' should be done and ' why'. The 'how' is presented in section 4, which introduce the reader to the chosen method and the cases studied in this project.

Regarding the development of the framework, section 5 presents the content of each paper included in this thesis. Each paper develops a certain part of the framework, but the compilation of each part is presented in section 6 . After reading section 5 , the reader should see how each paper contribute to the thesis objectives. After reading section 6 , the reader should have a clear view of how the framework is developed and why it is 
designed as it is. The reader is, in section 7 , demonstrated to what contributions this project does and what is left to do. 


\section{Supply Chain Management and Construction}

This section sets out to describe what Supply Chain Management (SCM) is perceived to be and how it is adapted in the construction industry. Difference between logistics and supply chain management is also presented. This is done together with a review of 'commonly occurring problems' in the construction industry. After reading this section, the reader will understand why a standardised framework for mapping and measuring supply chains are important. However, this discussion is presented in section 3. Scope and Purpose.

\subsection{Supply Chain Management and Logistics}

Before defining what supply chain management and logistics are and what make them different from each other, it is appropriate to define a supply chain. Stevens (1986) define a supply chain as:

"The connected series of activities which is concerned with planning, coordinating and controlling material, parts and finished goods from suppliers to the customer." (Stevens 1986)

It concerns both the flow of material and the flow of information, as highlighted by CSCMP (2013). La Londe and Masters (1994) mean that any company that sources materials and/or sells products has one or more supply chains linked to the organisation. Regardless of whether these chains or links are managed or not, they still exist (Mentzer et al. 2001).

\subsubsection{Supply Chain Management}

The term supply chain management (SCM) has been around since the early 1980's when it was coined by the consultant Keith Oliver (Harland 1996). However, the concept of SCM had been around for a while but no one had put a name on it. A problem still today is that the concept is ascribed many different meanings, and the work with unite over one definition has not been an easy task (Mentzer et al. 2001). The perspective of SCM has in the history been divided into a management philosophy (a supply chain is a single entity), a set of activities to implement a management philosophy (the activities of SCM), and a set of management processes (processes thinking) (Mentzer et al. 2001). One definition pronounced by the Association for Operations Management (APICS) is that:

"[SCM concerns the] design, planning, execution, control, and monitoring of supply chain activities with the objective of creating net value, building a competitive infrastructure, leveraging worldwide logistics, synchronizing supply with demand and measuring performance globally." (APICS 2013) 
The focus in this definition is on the physical movement of materials on global market. The definition does not say anything about relations between stakeholders in the supply chain. A problem is that APICS's definition also contains 'objective' aspects; you have not implemented SCM if you have not "leveraged worldwide logistics" or "created net value". APICS's definition can be compared with the one promoted by the Council of Supply Chain Management Professionals (CSCMP):

"Supply Chain Management encompasses the planning and management of all activities involved in sourcing and procurement, conversion, and all logistics management activities. Importantly, it also includes coordination and collaboration with channel partners, which can be suppliers, intermediaries, third-party service providers, and customers. In essence, supply chain management integrates supply and demand management within and across companies. Supply Chain Management is an integrating function with primary responsibility for linking major business functions and business processes within and across companies into a cohesive and high-performing business model. It includes all of the logistics management activities noted above, as well as manufacturing operations, and it drives coordination of processes and activities with and across marketing, sales, product design, finance, and information technology. " (CSCMP 2013)

This definition explicitly highlights that SCM not only involves activities for managing the flow of material but also for managing the relationship with different stakeholders. Mentzer et al. (2008) write about that this relationship aspect is something that is questioned by some authors. Ellram and Cooper (1990), for example, argue for the inclusion of the end customer in the definition. What is also interesting in CSCMP's definition is that they clearly describe that logistics management is a part of SCM and not the other way around. This is what Larson and Halldorsson (2004) would call a unionist perspective (see Figure 2), where logistics activities are a part of the SCM concept. The other three perspectives are called traditionalist (SCM is part of logistics), re-labelist (SCM is just a new word for logistics), and intersectionist (SCM and logistics are two separate topics witch overlaps). In this thesis, SCM is considered to be the management of all activities in the physical flow and information flow in the supply chain, which also includes the relationship with suppliers and customers, i.e. adhering to CSCMP's definition and being a unionist.
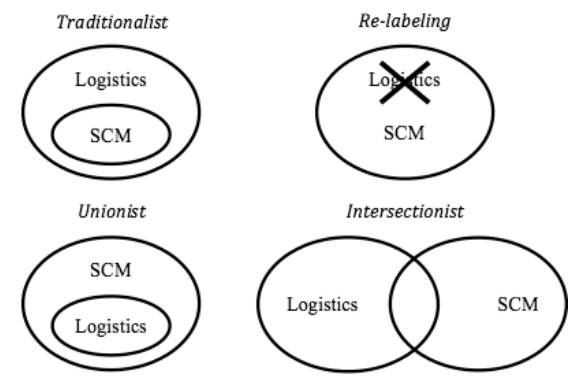

Figure 2: The different perspective on SCM and logistics proposed by Larson and Halldorsson (2004).

What is important to remember is that "one size does not fit all". Fisher (1997) and Stefansson and Russell (2008) claim that different types of products and supply chains 
call for different types of management. Fisher (1997) exemplifies this with the management of e.g. canned soup (with a stable demand pattern and of functional character) differs from e.g. winter garment (with seasonal demand and innovative character). Lambert and Cooper (2000) add to this discussion and call for different management of different suppliers and customers. Some 'links' in the chain should just be monitored whilst crucial links should also be managed.

\section{Logistics and its Connection to SCM}

One common question is what distinguishes logistics from SCM. CSCMP defines logistics as:

"The process of planning, implementing, and controlling procedures for the efficient and effective transportation and storage of goods including services, and related information from the point of origin to the point of consumption for the purpose of conforming to customer requirements. This definition includes inbound, outbound, internal, and external movements." (CSCMP 2013)

CSCMP also defines logistics management as:

"Logistics management is that part of supply chain management that plans, implements, and controls the efficient, effective forward and reverse flow and storage of goods, services, and related information between the point of origin and the point of consumption in order to meet customers' requirements.(...)", (CSCMP 2013)

This implicitly means that logistics is, as discussed earlier, a part of SCM. CSCMP (2013) also directly claims that the management of logistics activities (logistics management) is a part of SCM. Larson and Halldorsson (2004) conclude that SCM in the beginning of 2000 was, according to academic authors, vaguely defined and just a new name for logistics. However, there has been a shift in this opinion. One of the clearest statements of a shift in opinion was when the former Council of Logistics Management (CLM) changed its name to Council of Supply Chain Management Professionals (CSCMP) and explicitly marked that logistics is a part of SCM (Mentzer et al. 2008).

Mentzer et al. (2008) scrutinized the contemporary literature (up to year 2007) to see how different authors distinguished logistics management (LM), SCM, and operations management $(\mathrm{OM})$. They concluded that the topic is coloured by personal perceptions and no view is more correct than the others. However, their perspective on the matter is that logistics is a sub-set to SCM and that logistics activities cross both the SCM and OM sphere (Mentzer et al. 2008).

\subsubsection{Effects of Implementing SCM and Potential Barriers}

Ellram and Cooper (1990) describe that many companies implement SCM principles to reduce inventories, reduce supplier base, improve total cost efficiencies, and increase operation speed. Implementing SCM principles are not an easy task. Quayle (2003) identified that two of the biggest concerns are the lack of guidance on how to implement SCM and knowledge in SCM. This often results in fruitless attempts that just end up in costly failures. One of the reasons for not knowing what SCM is and why implementations fail is, as Mentzer et al. (2001) describe, that the companies has just started with implementing the Supply Chain Orientation (SCO), i.e. the philosophy of 
SCM, and not aligned the daily work with this philosophy. Patel et al. (2013) elaborates on this concept and argue that in order to reap the benefits of SCM principles the philosophy and the activities must be synchronised.

As Lambert and Cooper (2000) describe, one aspect of SCM is to integrate the supply chain and to manage (or monitor) this linkages. Vickery et al. (2003) could in their article present that integrating and managing the supply chain can have a positive effect on customer service (e.g. delivery speed, responsiveness, etc.) and improve financial performance (return on assets, return on investment, and return on sales). However, this requires that an information technology system is implemented and that customers, suppliers, and the focal company are willing to share information (such as demand patterns). Unwillingness to share information can be a barrier for implementing SCM (Lambert and Cooper 2000). But if this barrier is overcome, the effect of the so called 'Bull-Whip effect' could be reduced and result in reduced lead times, inventory levels, and costs to the customer (Power 2005).

Another aspect with implementing SCM principles is the potential improved relationship with both suppliers and customers (Lambert and Cooper 2000). The improved relationship can also positively affect the time and cost aspects as a better knowledge of what the customers wants and earlier integration of suppliers can create trust among members and minimise conflicts and misunderstanding (Hsu 2005). Shin et al. (2000) argue that the flexibility of the supply chain can increase and the cost be reduced as the numbers of suppliers can be reduced. This could also result in an increasing risk, as the chain becomes dependent on a smaller number of suppliers (Lambert and Cooper 2000). Although, improvements due to a better relationship can easily be lost as the unwillingness (as described above) to share information and cooperate can be a barrier for implementing SCM (Lambert and Cooper 2000).

Finally, detecting the effects of implementing SCM principles is difficult, as the content and meaning of SCM is questioned. This leads to that it becomes difficult to see how SCM as such affects overall performance. SCM can be seen as a 'black box' with many different 'tools' (ERP, integration, JIT, etc.). If the encountered effects are due to 'benefits' of SCM or any of the 'tools' is difficult to determine. The next section will describe how supply chains can be measured and how to assess SCM effects.

\subsubsection{Performance Measurement in Supply Chains}

Larson and Halldorsson (2004) pinpointed that the difference between SCM and logistics could be strategic vs. operational aspects, where SCM regards setting up the strategic relationships and logistics regards the actual operational transaction of goods (for example). Most metrics suggested for measuring the performance of the supply chain regards aspects that would be ascribed to logistics (cf. Brewer and Speh 2000, Gunasekaran et al. 2001). These metrics concern e.g. lead times, order fulfilment, and costs. The common way to assess supply chain performance (and maybe the effect of SCM) could be through measuring its logistical performance. Brewer and Speh (2000), however, elaborate on the idea that companies should not only assess these traditional 
measures, but also e.g. supply chain flexibility. It is not surprising, however, that one chooses to measure these traditional aspects when it comes to assessing SCM effects, as the most common reasons for implementing SCM is to reduce lead times, satisfy the customer, reduce costs, reduce inventory, etc. (Houlihan 1985, Stevens 1986, Lambert and Cooper 2000).

One of the first, and most difficult, things to do when embarking a measurement project is to define what to measure and what to not measure. Just because we can measure something it does not necessary mean it is of importance for us. It could even be the other way around; by measuring something just because we can we might end-up in focusing on the wrong things (Caplice and Sheffi 1994).

Caplice and Sheffi (1994) state that a proper logistic metric must be integrative, robust, useful, and valid. In order to be integrative a metric must consider all firms within a process and supply chain, not just focusing on one function or firm and sub-optimising. The robustness of a metric is defined based on how well received it is among all members and if the metric means the same for all members. A metric is considered valid if the outcome of using the metric is what we anticipated, we cannot measure the cost if we want to find out the time spent on a certain activity. Finally, a useful metric is believed to be understood by all members and can easily be used to guide the daily work. Caplice and Sheffi (1994) also identify potential trade-offs between these four criteria. Being more integrated could lead to a less useful metric and being more robust might conflict with the validity of the metric (a metric that is accepted by all members might not measure anything useful at all).

It is common in SCM and logistics measurement literature to distinguish between financial and non-financial metrics. One of the proponents of the former is Christopher (2011). He proposes that logistic performance among others should be measured based on return on investment. A problem is that many soft parameters (like a good relationship with the customer) that cannot be translated into dollars and cents are neglected. However, these parameters can have a huge contribution to the success (or failure) of a supply chain (Brewer and Speh 2000). However, a financial metric that deserves great attention is the total cost of the supply chain (Fawcett and Cooper 1998). By identifying the total cost through the supply chain the activities that create the most costs can be identified. However, a change in the cost structure (like reducing inventory at one company) at one point in the supply chain might impact the cost structure at another point (increasing inventory at another company).

In order to effectively control the processes in a supply chain it is necessary to develop and maintain a system for keeping track of measurement information (Gunasekaran et al. 2004). Despite the necessity of a measurement system, Fawcett and Cooper (1998) report on a lack of a proper systematic procedure for gathering necessary measurement information. Both Gunasekaran et al. (2004) and Caplice and Sheffi (1995) offers two different systems for performance measurement. 
In the Performance Measurement System (PMS) proposed by Gunasekaran et al. (2004) different metrics are allocated based on whether they belong to plan, source, make, or deliver processes. They also allocate the metrics based on whom they are suited for; strategic, tactical, or operational managers. Caplice and Sheffi (1995) on the other hand focus their view on the evaluation of existing performance measurement systems. A good logistics performance system should be comprehensive, causally oriented, vertically integrated, horizontally integrated, internally comparable, and useful. The system is comprehensive and causally oriented if it keeps track on causes and not just end results that take all stakeholders perspectives into consideration.

The two most common PMS around are the Balanced Score Card (Kaplan and Norton 1992) and Performance Prism (Adams and Neely 2000). In the Balanced Score Card, outcomes and internal process performance are balanced. The model does not only look at the financial past, it also drives focus to future performance. Adams and Neely (2000) blame the Balanced Score Card for overlooking the importance to see the employees, suppliers, intermediaries, regulators, and communities as stakeholders. Performance Prism includes five facets: stakeholder satisfaction, strategies, processes, capabilities, and stakeholder contribution. Najmi et al. (2012) blame both the Balanced Score Card and the Performance Prism to lack in evaluation of the models' benefits. They suggest a framework for how to evaluate the Performance Prism model. For example, a feed-back loop is suggested, so evaluation of relevant metrics is considered and how effective the implementation of the model is.

Another perspective highlighted by Bai and Sarkis (2012) is that even though the number of PMS is vast, very few of them is considering logistics and SCM aspects. They develop a framework for assessing current measurements' result on logistics outcome. This framework can according to Bai and Sarkis (2012) be used to analyse which metrics that are most important to considered, depending on desired logistics outcomes. Thakkar (2012) is coherent in the view that supply chain performance is overlooked in many PMS, to advantage for internal process performance. One of the key ingredients in a successful supply chain PMS is to align processes among the members and find metrics that measures the whole chain and not a single member. One barrier could be that this metric might be of disadvantage for one member, it is important then to remember that the goal is to assess the whole supply chain performance and not a single member. Thakkar (2012) also highlight that more research in evaluating existent models is important; are they beneficial or not?

\subsection{Construction Supply Chain Management}

Since early 1990's an adoption of logistics and SCM to the construction industry has been a hot topic. One of the first reports on this matter was the doctoral thesis of Koskela in 1992. The perspective on SCM has shifted, from a set of logistic tools for improving project performance to a way of integrating members in the construction project. This shift affects the reasons for why adopting logistics and SCM principles. Another hot-topic is what distinguishes SCM from the Partnering concept. The debate, on what construction 
SCM really is, is still on-going. This chapter will outline the change in perspectives on construction SCM.

\subsubsection{The Perspective on SCM as Logistic Tools}

The term SCM is a relative new concept to the construction industry, even though the concept of supply chains is not. The two seminal works produced by Latham (1994) and Egan (1998) suggests that many of the problems (planning issues, reworks, defects, etc) in the industry lead to reduced productivity and increased costs. However, some authors challenge the declined productivity (e.g. Song and Lind, 2012). Even so, Song and Lind (2012) have a macro perspective on productivity, if a micro view is utilized the productivity is reducing (Josephson 2013). Latham (1994), Egan (1998), and Vrijhoef and Koskela (2000) suggest that the problems facing the industry could be overcome through better coordination of members in the supply chain. Another view than the integration and coordination that has received focused from academic authors is the view on taking logistical tools from the manufacturing industry to improve construction performance.

One example is the Last Planner System (LPS) developed throughout the 1990's by Glenn Ballard, presented in Ballard (2000). The LPS is a tool based on Lean principles for better planning of activities, procurement, and resources on site and among members. Another 'tool' often cited as a remedy to the problems in the industry, is Just In Time deliveries (JIT). Bertelsen and Nielsen (1997) report on an overuse of express deliveries to construction sites and a lack of material delivery scheduling and that using JIT would benefit the industry. Yet, Vidalakis et al. (2011) prove that not all members in the supply chain reap the benefits with adopting the JIT tool. Their simulations results are based on the idea that all materials are of low-value and high-volume character, which is not always true (e.g. windows are not of low-value). Other authors suggest that a version of the reorder point system (Caron et al. 1998) or resources allocation systems (Faniran and Love 1999) could have a positive effect on costs and productivity.

\subsubsection{SCM as a Means to Integrate Members}

One of the most cited papers is the work presented in the year 2000 by the two researchers Vrijhoef and Koskela, who defined the four roles of SCM in construction. After them, much research has been focused on what SCM in construction really is. Vrijhoef and Koskela (2000) describe that many of the problems have their origin earlier in the supply chain, but their effects propagate to the construction site. They portrayed the focus on SCM in construction as four roles: focus on the integration of the supply chain and site activities, improving the whole supply chain, transferring site activities to the supply chain, or integrating the supply chain and the site. However, Saad et al. (2002) conclude that even if the industry deems SCM as a means of overcoming common problems it is not prepared for it and do not understand the concept of it. Green et al. (2005) and Fernie and Thorpe (2007) also highlight the fact that SCM cannot be adopted as it is, it most likely need to be adapted to construction contexts.

The belief today is that SCM can be used to integrate members to better coordinate the work in the supply chain. For example, Karim et al. (2006) discuss the need of main 
contractors to better manage subcontractors' supply chains as subcontractors stand for a great portion of the work on site and therefore also the number of defects. The question is why the industry would like to adopt SCM? Akintoye et al. (2000) performed a survey on this matter and concluded that the main objective among practitioners to implement SCM was to bring benefits to the client and improve customer service. It is not difficult to understand why most contractors engage in collaboration with clients rather than with suppliers (Akintoye et al. 2000). Jang et al. (2003) identified that a client's satisfaction depends on service quality, product quality, and price, as logistics costs represent some 39 $\%$ of the total project cost, better logistics could have a great impact on client satisfaction. Also quality can be improved with better logistics. Akintoye et al. (2000) also conclude that trust among members is an important factor for efficient SCM implementation and that a lack of top management commitment is the main culprit for poor implementation success. Yet, a trustful climate is not something that is present in the industry (Dainty et al. 2001). Tennant and Fernie (2013) report that top management commitment could be lacking due to a lack of understanding of what SCM is. The concept of SCM in construction is often discussed around if it focuses on material deliveries or relationship (cf. Akintoye et al. 2000 and Baladhandayutham and Venkatesh 2012).

An issue to consider when discussing integration of supply chain members is how a construction supply chain looks like. A great deal of the work performed on-site is allocated to subcontractors and special trades, and much material is of a high-value, lowvolume character (like windows). Cox and Ireland (2002) also identify that a construction project houses many different kinds of 'supply chains': resources, labours, materials, and information. They furthermore raise the question regarding power in the chain; can a chain with a strong supplier be managed in the same sense as a chain with a strong contractor or client? As an addition to this, Dubois and Gadde (2002) confirm that construction projects often have a myopic view to coordination. They describe the construction supply chain as loosely coupled system consisting of four types of coordination issues: within projects, supply chain, firms, and among firms beyond the project. Two projects within the same firm are quite autonomous and neglect the benefits of coordination e.g. resources among projects. Problems with coordinating work among members in the project and beyond each project lead to sub-optimisation and learninginabilities, which is a fact still today (cf. Lönngren et al. 2010). Even if collaboration is seen as a necessity to remedy the problems in the industry the practitioners do not see a clear difference between SCM and partnering (Akintoye et al. 2000). The question is then, are there any differences?

\subsubsection{SCM vs. Partnering}

It has for a long time been discussed what the concept of partnering really means (Bresnen and Marshall 2000). The overall theme with partnering is for two (or more) members in a construction project to work jointly to achieve mutual objectives. Therefore, traditional adversarial arms-length relationships should be set aside for cooperation. It is believed that partnering can help to adhere to the time schedule and the budget. However, as Eriksson (2010) claims, partnering does not per se mean that a 
project will be successful. A problem with partnering is that for a long time it has been a discussion on what it really is (cf. Bresnen and Marshall 2000). The problem then, is that it gets difficult to assess how successful it has been utilised in a project. What was due to the use of partnering and not?

The definition of SCM made by CSCMP's (2013) could be condensed to be about working together in the supply chain to manage activities and in the end bring value to the end customer. This coincides somewhat with the perspective on what partnering is: to work together to bring value to the customer. It is not difficult to understand why SCM and partnering is perceived to be the same thing among practitioners. Although, Bygballe et al. (2010) discuss that while SCM focuses on long-term contractual relationships, practitioners use partnering on short-term project basis without contracts. They also conclude that partnering concepts often focus on relation between clients and main contractors, and pay little attention to suppliers and subcontractors. Even if a long-term approach (also including sub-trades) is deemed important, it is equally important to prioritize whom to cooperate with and how it affects other relationships. Fernie and Thorpe (2007) argue that SCM is often believed to be the solution to all problems but fail in practice. That is due to construction practitioners' willingness to adapt it as a best practice from the manufacturing industry without thinking of contextual differences. Partnering could then be seen as an adapted version of SCM suitable for construction, but with some important differences from traditional SCM (like not considering suppliers).

The final question to raise then is how SCM (or partnering) should be implemented and by whom? Even here are the suggestions diverse. Some argues that the client should take greater responsibility (Dainty et al. 2001) while others promote the builders merchants (Vidalakis et al. 2011). However, Bygballe et al. (2010) argues that the main contractor should be responsible as they are positioned as a natural link between many converging chains in the network. Although, many argue that if not the client specifically ask for cooperation in the bidding process, it will probably not be carried out.

\subsection{Construction Logistic Issues}

As for many other industries (if not all of them) the ultimate task for a construction company is to produce according to a customer's specific requirements on cost, time, and quality. This is what some authors call the 'iron triangle' (Toor and Ogunlana 2010). It is of course difficult to have high quality and to be both low cost and fast (Atkinson 1999). This chapter aims not to give an introduction to how a company can decide on to be either fast, low cost, or have a high quality. This chapter aims to give an introduction to what the common problems in the construction industry are.

A situation can be either considered a problem or a symptom of a problem. It was discussed earlier that the construction industry is facing decreasing productivity and increasing cost (Vrijhoef and Koskela 2000). However, are these two 'facts' the problems or the symptoms? The question is: what are the problems and what causes these problems to affect the cost and productivity negatively? 
Vrijhoef and Koskelas (2000) reported on how problems arise early in the supply chain and propagated to the construction site. This chapter focuses on the problems on-site (ending up in increased cost and decreased productivity) and what causes them, by looking at the supply chain. It is an on-going debate on whether the costs are increasing and the productivity are stagnating (cf. Song and Lind, 2012). Even if the debate is sound, this thesis relies on statistics from Statistics Sweden (SCB 2013) and Josephson and Saukkoriipi (2005). SCB (2013) indicates that the Building Price Index (BPI) is increasing more rapidly than the consumer price index (CPI), see Figure 3. Collectively one- or two- dwelling buildings (Swe: Gruppbyggda småhus) are one-family houses built collectively for renting or selling purposes.

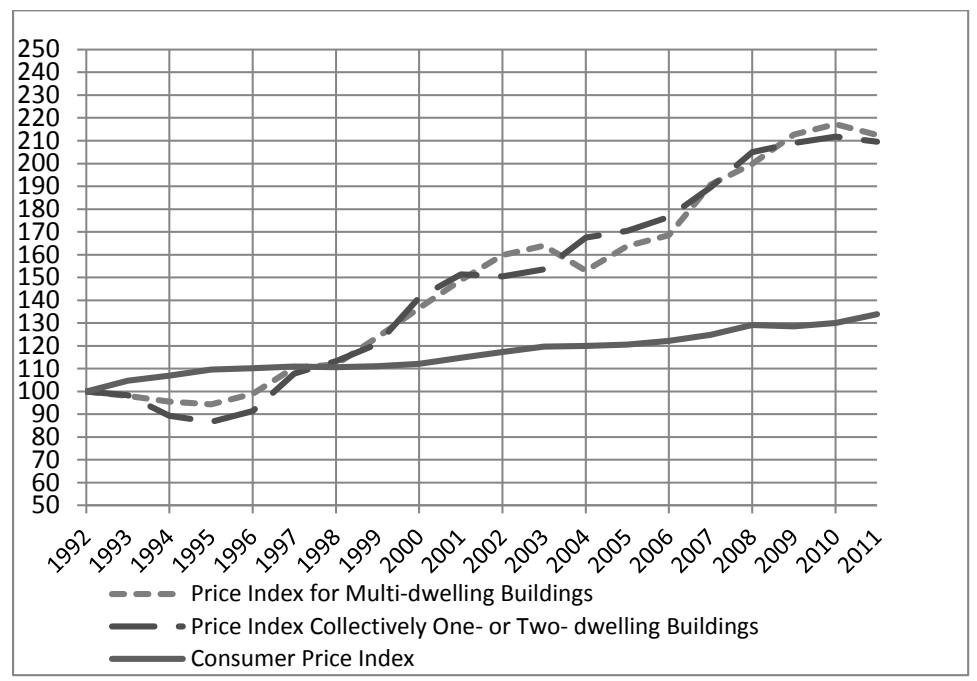

Figure 3 : Development of Building Price Index (BPI) from 1992 to 2011, source SCB (2013).

Josephson and Saukkoriipi (2005) report an interesting perspective on what a craftsman spend his or her time on a regular day, see Figure 4. These two aspects indicate that the productivity deteriorates in the construction industry, see also Josephson (2013).

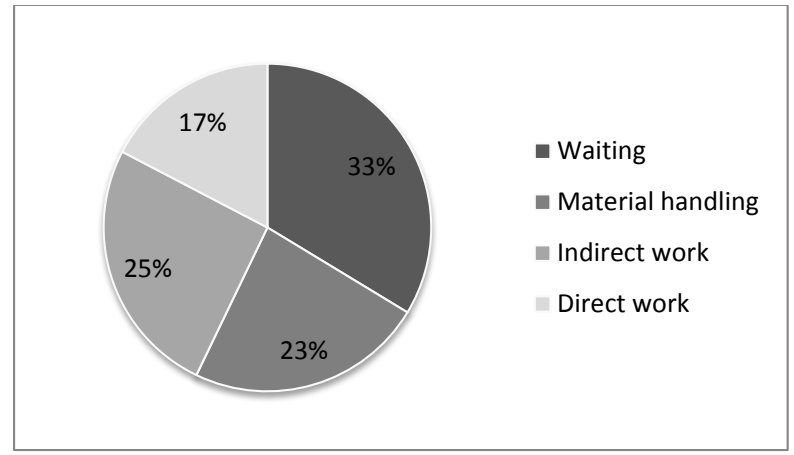

Figure 4 : Time spent by craftsmen on certain activities a typical working day, source Josephson and Saukkoriipi (2005). 
Many researchers believe that paying more attention to logistics and implementing SCM principles will have a positive effect on the time and cost overruns, the productivity, quality, and even safety (Agapiou et al. 1998, Akintoye et al. 2000, Meng 2012). The following section will describe construction supply chain characteristics.

\subsubsection{The Construction Supply Chain}

\section{Temporary Organisations}

The production of building objects is in almost every case conducted in a project form, hence the term construction project. Compared to a static firm, a project is defined by a clear start and end time period (PMI 2013). The life of a construction organisation is therefore as long as the construction project in itself. This means, that the organisational structure for the project is born and dies with the project.

Some authors argue that the ability to learn from one project to another is inhibited due to this use of temporary organisations (Meng 2012). A more stable organisation structure, that lasts over several projects, could be deemed necessary (Love et al. 2004, Modig 2007). For example, if a solution to one problem is developed during one project it is seldom handed over to other projects (cf. Dubois and Gadde 2002). Another problem with the fact that new organisational structures have to be developed for each project is that the built-up trust among members fades (Bygballe et al. 2010). This trust has to be rebuilt with new members for the next project.

It is often claimed that the temporary nature and other uncertainties in the industry has a negative impact on the cost and time (Son and Rojas 2011). A considerable portion of the outset-phase is devoted to building up the organisation and the supply chain and to build up trust. If the supply chain and the organisational structure already exist from the beginning, less time has to be spent on this phase. Plus, the risk of conflicts due to lacking trust will probably decline (Chua and Kog 1999). This can have a positive effect on cost, time, and safety.

\section{Fragmented Industry}

Another characteristic of the construction industry is that it is fragmented, which means that the industry consists of many small companies. Figure 5 below indicates that in Sweden (year 2007) most construction companies had few employees but a small number had more than 500 employees. As can be seen, most of the craftsmen (62.5\%) in the construction industry are hired by companies with few employees. However, $37.5 \%$ of the craftsmen are hired by a company which employed more than 500 craftsmen. A total of seven companies hired more than 500 employees and 18210 companies hired less than 500 employees, most of the companies, in total 10759 , had no employees at all. (SCB 2013) 


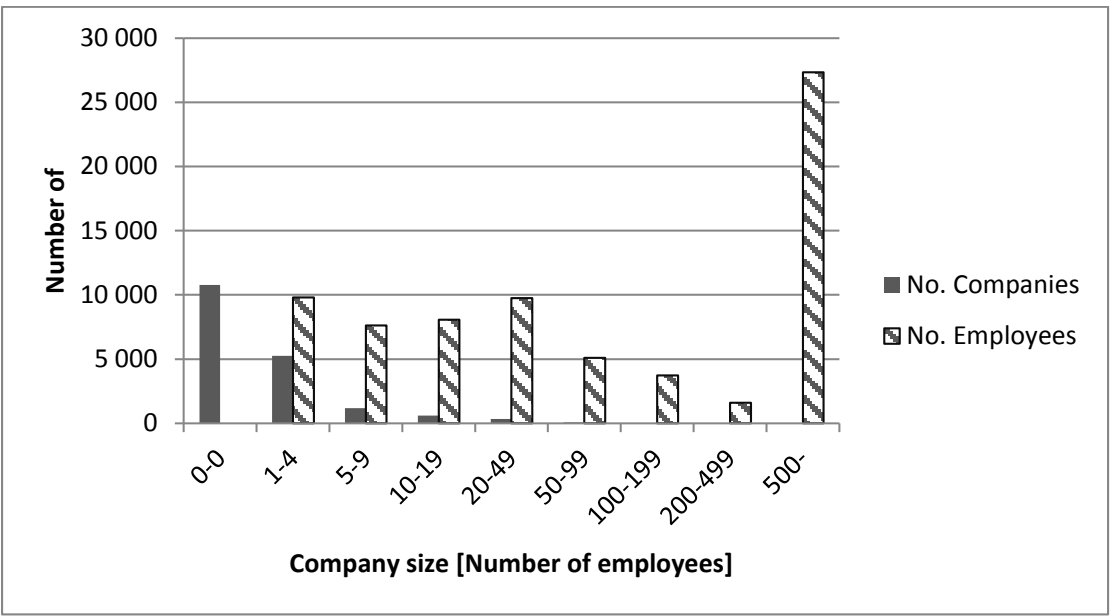

Figure 5 : Number of employees in comparison with company size.

What does this fragmented nature means for the performance of the construction industry? Fearne and Fowler (2006) report that this fragmentation, with many small companies, creates uncertainty in the projects. A problem with many companies working on the same project is the coordination issue (Dubois and Gadde 2000, Gidado 2004). The more parties to involve in the planning of the construction the more difficult it gets. Lack of coordination has been reported on being the culprit of much rework on-site (cf. Love and Edward, 2004). If plans and work activities are not coordinated it can have a negative impact on the performance, and in the end causes extensive cost and time overruns.

A third characteristic with the construction industry is that each construction project is autonomous (Dubois and Gadde 2000). Each project acts as an independent firm without too much involvement from the parent company. This can lead to information and coordination problems as knowledge from different project are not shared among all company projects (cf. Bygballe et al. 2010).

\subsubsection{Planning in Construction}

\section{Pre-construction vs. On-site Planning}

Planning in construction can typically be separated in two planning processes, often entitled pre-construction and on-site planning (Johansen and Wilson 2006). The preconstruction planning process is more strategic and tactical, and consists of: selection of project team; creation of the project documentation system; initiating the purchasing of materials; development of the schedule and milestones; and other pre-project-execution activities (Menches et al. 2008). The on-site planning is, on the other hand, more operational and focuses on: ensuring that planned activities can be fulfilled; schedule adherence; material procurement; weekly meetings; etc. (Johansen and Wilson 2006).

Research has typically focused on the technical part of planning (Laufer and Tucker 1987), especially when it comes to on-site planning. By studying the literature (Mainul 
Islam and Faniran 2005) one can still see a focus on the development of advanced mathematical models for improving scheduling techniques (e.g. Mohamed 2001, Arditi et al. 2002, González et al. 2009, Soekov and Lill 2011). These techniques are, however, not useful if companies do not solve the structural planning problems that exists in the construction industry (Laufer and Tucker 1987). Effective planning should ensure that all involved actors know what to do, when to do it, and that the required resources are available. SCM can be a facilitator for effective planning, and many authors stress the inclusion of subcontractors and suppliers in construction planning. Agapiou et al. (1998) argue that the productivity of construction projects would increase if logistic issues (like scheduling of materials, etc.) were given greater attention in the planning process.

Another important part of planning is to coordinate the work with other project participants, like confirming that all participants share the same view of what the project goals are (Fellows 2009). As such, one should not see pre-construction and on-site planning as two isolated processes (Laufer and Tucker 1987, Johansen and Wilson 2006, Menches et al. 2008). Rather, the on-site planning process is to a high degree affected by the decisions made in the pre-construction planning phase, especially when it comes to SCM and logistics issues. SCM is mainly about coordination and involvement of subcontractors, suppliers and consultants in the project. Yet, Fellows (2009) describes that coordination is most often absent in construction projects, which leads to unshared goals between participants and unsuccessful projects. This and other, similar, problems in construction planning are described in the following section.

\section{Common Planning Problems}

Analysing papers that report on construction planning reveals that common planning problems often stem from aspects like relationship management, information management, planning complexity and resources planning. Table 1 summarises the different problems and their respective effect on the pre-construction and/or on-site planning processes.

Starting with relationship management, Johansen and Wilson (2006) point out that planning often means different things for different participants. Therefore, a closer relationship between participants can reduce unfamiliarity and avoid planning mistakes and excessive rework (Menches et al. 2008). The importance of non-exclusion of subcontractors is also emphasized (Johansen and Porter 2003, Gidado 2004) to increase the transferability of knowledge between participants.

In terms of information management, there is often an information shortage due to lack of information gathering and distribution between and among participants (Laufer and Tucker 1987). This also leads to that planning problems and lessons learned are not shared between projects (Kelsey et al. 2001). The lack of information and an inadequate cognition can likewise affect the estimation of durations, often leading to scheduleoverruns (Soekov and Lill 2011). Ballard and Howell (2003) mention that waste in terms of waiting time can occur when not interdependency is considered. This can lead to that resources are not sufficiently utilized and that succeeding activities have to be postponed. 
Table 1 : Planning problems and their effects on the construction phase.

\begin{tabular}{|c|c|c|c|c|}
\hline & Problem & Pre-construction & On-site & References \\
\hline \multirow{4}{*}{ 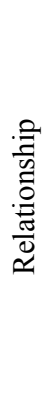 } & Different meanings & $\begin{array}{l}\text { Increased amount of } \\
\text { rework as plans has to be } \\
\text { changed }\end{array}$ & & $\begin{array}{l}\text { (Gidado 2004, } \\
\text { Johansen and } \\
\text { Wilson 2006) }\end{array}$ \\
\hline & Exclusion & $\begin{array}{l}\text { Suppliers unaware of the } \\
\text { project's needs. }\end{array}$ & $\begin{array}{l}\text { Suppliers unaware of the } \\
\text { project's needs. }\end{array}$ & $\begin{array}{l}\text { (Kelsey et al. } \\
\text { 2001, Gidado }\end{array}$ \\
\hline & & $\begin{array}{l}\text { Problems with material } \\
\text { deliveries }\end{array}$ & $\begin{array}{l}\text { Problems with material } \\
\text { deliveries }\end{array}$ & $\begin{array}{l}\text { 2004, Johansen } \\
\text { and Wilson } \\
\text { 2006) }\end{array}$ \\
\hline & Unfamiliarity & $\begin{array}{l}\text { Excessive reworks and } \\
\text { changes }\end{array}$ & & $\begin{array}{l}\text { (Menches et al. } \\
\text { 2008) }\end{array}$ \\
\hline \multirow{3}{*}{ 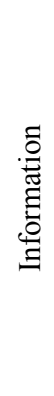 } & $\begin{array}{l}\text { Information } \\
\text { shortage }\end{array}$ & $\begin{array}{l}\text { Misallocation of } \\
\text { materials, poor } \\
\text { preparation, no } \\
\text { information or } \\
\text { improvement of plans }\end{array}$ & $\begin{array}{l}\text { Variety in planning and } \\
\text { where to place materials } \\
\text { etc. }\end{array}$ & $\begin{array}{l}\text { (Laufer and } \\
\text { Tucker 1987, } \\
\text { Kelsey et al. } \\
\text { 2001) }\end{array}$ \\
\hline & $\begin{array}{l}\text { Inadequate } \\
\text { cognition }\end{array}$ & & $\begin{array}{l}\text { Increased flaws and } \\
\text { reworks as plans are } \\
\text { poorly developed }\end{array}$ & $\begin{array}{l}\text { (Soekov and Lill } \\
\text { 2011) }\end{array}$ \\
\hline & Interdependency & & Waiting time waste & $\begin{array}{l}\text { (Ballard and } \\
\text { Howell 2003) }\end{array}$ \\
\hline \multirow{4}{*}{ 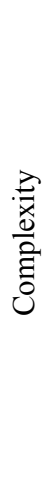 } & Project uncertainty & & $\begin{array}{l}\text { Poor and faulty plans and } \\
\text { Schedule variance }\end{array}$ & (Laufer 1991) \\
\hline & Local variations & & Schedule overruns & (Mohamed 2001) \\
\hline & Dynamic projects & & $\begin{array}{l}\text { Poor decision-making and } \\
\text { non-realistic out-puts, } \\
\text { lack of resources when } \\
\text { needed }\end{array}$ & $\begin{array}{l}\text { (González et al. } \\
\text { 2009) }\end{array}$ \\
\hline & Intricacy forgotten & $\begin{array}{l}\text { Impacts time, quality, } \\
\text { value, number of conflicts } \\
\text { and safety }\end{array}$ & & $\begin{array}{l}\text { (Laufer and } \\
\text { Tucker 1987, } \\
\text { Gidado 2004, } \\
\text { Menches et al. } \\
\text { 2008) }\end{array}$ \\
\hline \multirow{4}{*}{ 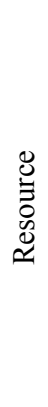 } & Hastiness & $\begin{array}{l}\text { Increasing risk level and } \\
\text { financial commitment }\end{array}$ & & (Gidado 2004) \\
\hline & $\begin{array}{l}\text { Rate and } \\
\text { repetitiveness }\end{array}$ & & Waiting time waste & $\begin{array}{l}\text { (Arditi et al. } \\
\text { 2002) }\end{array}$ \\
\hline & $\begin{array}{l}\text { Workflow } \\
\text { planning }\end{array}$ & & $\begin{array}{l}\text { Wrong tasks performed at } \\
\text { the wrong time create } \\
\text { conflicts. }\end{array}$ & $\begin{array}{l}\text { (Arditi et al. } \\
\text { 2002, Ballard } \\
\text { and Howell } \\
\text { 2003) }\end{array}$ \\
\hline & $\begin{array}{l}\text { Flows and } \\
\text { inventories }\end{array}$ & $\begin{array}{l}\text { Too much material on- } \\
\text { site }\end{array}$ & Too much material on-site & $\begin{array}{l}\text { (Kelsey et al. } \\
\text { 2001) }\end{array}$ \\
\hline
\end{tabular}


A part of the complexity of planning relates to project uncertainty leading to variability in material flows (Laufer 1991), which in turn affects the reliability of the plan and vice versa (Ballard and Howell 2003). Many authors report that this intricacy is forgotten (see Table 1) and too little attention is devoted to including the dynamic nature of a construction project Gonzáles et al. (2009). Local variations might lead to that resources are incorrectly allocated (Mohamed 2001).

Resource constraints like not enough time for pre-construction planning (hastiness) is a problem that often results in conflicts between participants (Gidado 2004). Arditi (2002) identify that the omitting of production rate and the repetitiveness nature of many projects might result in time wastes and schedule overruns. Planning should also consider the workflow (Arditi et al. 2002, Ballard and Howell 2003), as conflicts might arise when different craftsmen are planned to work at the same place. Also omitting material flows and inventories from the planning process often results in too much materials on-site (Kelsey et al. 2001).

\subsection{Performance Measurement in Construction Supply Chains}

One of the important questions to ask when doing a performance evaluation is 'what to measure'. The decision on what to evaluate can have significant impact on what kind of improvement action is taken. For example, if focus is put on customer satisfaction the improvement actions will also focus on improving it, even though the actual problem lies elsewhere. This sub-section describes the current literature on performance measurement in construction and what to measure.

All kinds of construction projects are about constructing a building object that satisfies the customer's expectations. This is done by sourcing and assembling raw materials and components. The building project is in this section divided into three constituting parts: the procurement of construction material part (let us call it The Input), the building process (The Process), and the order fulfilment part (The Output). The input is about selecting suppliers, purchasing materials, and to get the materials to the construction site. The building process is about constructing the building object. Finally, the output is about to make sure that the customer is satisfied and that the building object meets all requirements. Performance measurement in construction is a topic often in debate. Radujković et al. (2010) argue that the 'iron triangle' is the overall theme in assessing construction performance and consists of quality, cost, and time aspects. Most of the performance measurement literature thus discusses how these three aspects are affected. The subsequent sections below show how measurement within the input, the process, and the output are treated in connection to the 'iron triangle'.

\subsubsection{Measuring 'The Input'}

When it comes to the input part in the construction project important matters to analyse are e.g. supplier performance, material quality, lead times, inventory levels, etc. According to Kagioglou et al. (2001), much focus and attention from academia on 
performance measurement is put on the process and the output part. However, in order to reduce e.g. lead times and costs, it is a good idea to also pay attention to the input part.

Amornsawadwatana (2011) shows in a study that number of unloading activities and the total waiting time for a truck on-site can be reduced with about $24 \%$ and $33 \%$, respectively, if distribution centres (DC) are used. However, that also implies more extensive work on coordinating work and plans between the suppliers and the main contractor. Many authors (see Kelsey et al. 2001, Gidado 2004) report that a lack in synchronising plans and knowledge between the suppliers and the main contractor can highly impact overall project performance, like time overruns. Baladhandayutham and Venkatesh (2012) describe that about $16 \%$ of the incoming deliveries are arrived on time. It should be mentioned that these authors regard a delivery as on time if it arrives within 60 days before the desired delivery date. It can be argued that this is a quite extensive period. However, the number would not increase if the considered time period were shortened, rather the opposite.

Voordijk (2010) analyses what trade-offs exist in the distribution costs of construction materials. Among many things, he analyses how different order quantities affect the total cost and suggests a model for measuring the physical distribution cost. Vrijhoef and Koskela showed in year 2000 that problems in the earlier part of the supply chain affect overall project performance like the cost. They argued that the total cost could increase if material is purchased solely based on low cost parameters. This is also true for the time and quality aspects in the 'iron triangle'. If material quality deficiencies are not discovered in time, extensive reworks could be a fact if the materials are assembled (Vrijhoef and Koskela 2000).

The question on what to measure in the input part is a tough one; there is probably no straight answer to this question. The first question one should ask is on what criterion the company wants to compete with (cf. Kocaoğlu et al. 2011). If the company wants to compete based on cost aspects, then it is important to measure the input part based on costs. However, something that is collectively agreed upon in the academia is the importance of a well-functioning relationship between suppliers and contractors (Dubois and Gadde 2000, Amornsawadwatana 2011). Therefore, a metric for assessing supplier relationship can be of importance. Bemelmans et al. (2012) have created a measurement system for assessing a company's ability to manage suppliers. It is not a measurement of how well a certain relationship works; it is more of a measurement on an aggregated strategic level.

\subsubsection{Measuring 'The Process' and 'The Output'}

Common measurements suitable for evaluating the building process often concern waste levels, subcontractor performance, safety, assembly times, etc. Subcontractors accomplish a great deal of the work performed on the construction site. Karim et al. (2006) report that about $90 \%$ of the work performed on-site is allocated to subcontractors. Evaluating subcontractors work and the relationship (see Yeung et al. 2008) with the subcontractors thus become important, as the main contractor act as a project manager. Karim et al. 
(2006) also highlight that a non-functioning relationship with the subcontractors can have a negative impact on reworks, as wrong drawings are used etc. Love and $\mathrm{Li}$ (2000) concluded that in two studied projects the cost of reworks amounted to an average of $3 \%$ of the projects' contract value. Keeping track on the amount of reworks is important, as cost and time overruns otherwise can become a reality. In their article from 2005, Ling and Peh identify a total of 55 different performance metrics, ranging from customer satisfaction to waste management. Even if reworks and waste are two important elements, they concluded that the waste levels were next to employee turnovers the most infrequent performance element to measure among contractors.

Dawood (2010) suggests that the number of reworks could be reduced with implementation of 4D planning. In his paper, he develops nine metrics to use for assessing the use of $4 \mathrm{D}$ planning and construction performance. It ranges from client satisfaction to production lead time. In order to identify how much time is spent on a certain activity, Yu et al. (2009) suggest a use of value stream mapping (VSM). In their study where they used VSM, they found that the actual duration (for 400 houses) of the 'lock-up stage' (framing to roofing) could differ with $24 \%$ from the scheduled duration. Frödell et al. (2008) identified that all types of clients regarded a project as successful if it is kept within the budget, finished on time, and is delivered with a high quality. This might not be surprising, but Frödell et al. (2008) also stated that the clients considered that the concept of successful must be widened. One example could be to extend the concept of time measurement. Gidado (2004), as many other authors, highlight the fact that proper planning procedures have a positive impact on e.g. time aspects. It could be argued that also the client could be interested in a project's ability to plan. Proper aspects to measure are how often, to what extent, and where in the planning process the subcontractors and suppliers enter (Kelsey et al. 2001).

One element concerning the building process to measure is the concept of productivity. As described earlier, the term productivity is used in the current literature to either describe the situation in the industry on a macro or micro level. Song and Lind (2012) argue that productivity on a macro level is not decreasing, compared to the common perception. However, authors such as Josephson (2013) suggest that productivity should instead be assessed on a micro level, like measuring assembly time and number of reworks etc. He also point out that few companies do measure the subcontractors' assembly times, even though it could affect overall project duration.

Regarding measuring the output Frödell et al. (2008) report in their article that, what they called 'selling clients', do not prioritise time and quality predictions during the handover process. Instead the 'selling clients' prioritise metrics like return on investments and profitability. This can be a result of the fact that the selling clients will sell the building object and are not held accounted for the maintenance. For maintaining and using clients, important assessment elements would be how satisfied they are (Chan and Chan 2004, Yeung et al. 2008) and how many defects the building object is tainted with. Other aspects are if the project is ended within agreed-on time, budget, and quality frames Radujković et al. (2010). As discussed in previous subsection, it is difficult to exactly 
point on a certain metric for assessing construction performance. It depends on what overall strategy the construction company has and in what criterion the company wants its products to be order-winners in. It is however agreed on in the literature that time, cost, quality, and client satisfaction are four important aspects to consider when assessing project performance; even though some authors like Pheng and Chuan (2006) argue that these should not be the only metrics. 


\section{Scope and Purpose}

This section presents the scope, purpose, and objectives with this study. This section aims to clarify the purpose via extracting information from section 2 and use it as motivation. The SCOR model is thoroughly presented in this section together with descriptions of discrepancies between the SCOR model and the construction industry.

\subsection{Condense the Literature to Define the Scope and Purpose}

Section 2.2 Construction Supply Chain Management provided a flora of different problems facing the construction industry. The problems are both of general types but also of logistical kinds. Examples include everything from autonomous project organisations to not measuring supplier performance. All problems identified in section 2.2 Construction Supply Chain Management are summarised in Table 2.

Much of the identified problems listed in Table 2 concerns finding fruitful best practices for the industry to work on. Best practices could include topics like implementing Last Planner System (LPS) for planning, engage in Partnering for improve on relationships among project members, etc. The importance is to identify these best practices in the construction industry and report on the benefits of implementing them. However, one important issue to cope with before deciding on implementing best practices is how to evaluate the success of such an implementation. In order to do that, construction specific metrics have to be developed. But furthermore, before measuring the performance of a supply chain we first have to know what activities are performed in the chain. This includes that construction specific process definitions for mapping the supply chain have to be developed. To sum it up, a construction developed supply chain framework should include construction specific processes, metrics, and best practices. Table 2 also identify how a construction specific supply chain framework could aid in overcoming the identified problems.

As can be seen, a construction developed supply chain framework can aid in overcoming many of the identified problems. The purpose with the project presented in this thesis is to develop a framework for process mapping and performance measurement in construction supply chains. 
Table 2 : Problem areas and how a supply chain framework could aid.

\begin{tabular}{|c|c|c|}
\hline Problem areas & Description & $\begin{array}{l}\text { How can a standardised } \\
\text { framework aid? }\end{array}$ \\
\hline Lack of coordination & $\begin{array}{l}\text { Not coordinating work among } \\
\text { members might lead to extensive } \\
\text { reworks and a delayed project }\end{array}$ & $\begin{array}{l}\text { Via a procedure for how to plan } \\
\text { and distribute plans among } \\
\text { members }\end{array}$ \\
\hline $\begin{array}{l}\text { Not considering } \\
\text { contextual } \\
\text { differences }\end{array}$ & $\begin{array}{l}\text { 'Solutions' developed for other } \\
\text { manufacturing industries cannot be } \\
\text { transferred to the construction } \\
\text { industry }\end{array}$ & $\begin{array}{l}\text { Including construction 'Best } \\
\text { Practices', metrics, and } \\
\text { definitions solely developed for } \\
\text { the construction industry }\end{array}$ \\
\hline $\begin{array}{l}\text { Not improving } \\
\text { customer service }\end{array}$ & $\begin{array}{l}\text { A perceived lack of not focusing on } \\
\text { improving overall customer services }\end{array}$ & $\begin{array}{l}\text { Standardised system for } \\
\text { mapping and measuring that } \\
\text { contains relevant metrics }\end{array}$ \\
\hline $\begin{array}{l}\text { Not inhabiting a } \\
\text { trustful climate }\end{array}$ & $\begin{array}{l}\text { A hostile environment among project } \\
\text { members often stem from not } \\
\text { understanding each other, not } \\
\text { knowing what the others are doing, } \\
\text { and unstable relationships }\end{array}$ & $\begin{array}{l}\text { Predefined metrics and process } \\
\text { definitions results in talking the } \\
\text { same language. Identify } \\
\text { problematic relationships and } \\
\text { improve them. }\end{array}$ \\
\hline $\begin{array}{l}\text { Construction supply } \\
\text { chains are loosely } \\
\text { coupled }\end{array}$ & $\begin{array}{l}\text { Not learning from other projects, not } \\
\text { learning from other companies, } \\
\text { myopic climate, etc. }\end{array}$ & $\begin{array}{l}\text { Identify Best Practices and } \\
\text { report on them. Scrutinise the } \\
\text { supply chain and identify } \\
\text { problems to overcome }\end{array}$ \\
\hline $\begin{array}{l}\text { Not adhering to time } \\
\text { schedules and } \\
\text { budget }\end{array}$ & $\begin{array}{l}\text { How do we measure adherence to } \\
\text { time schedule and budget? } \\
\text { Adherence to time schedules and } \\
\text { budgets are not measured, compared, } \\
\text { and followed up systematically today }\end{array}$ & $\begin{array}{l}\text { Standardised metrics and } \\
\text { measurement to use for keeping } \\
\text { track on time and cost } \\
\text { adherence. Evaluate trends in } \\
\text { time and cost adherence. }\end{array}$ \\
\hline
\end{tabular}

Not learning from other projects

Fragmented industry

Autonomous projects

How to plan?

Not talking the same language

Not sharing information

Not measuring supplier performance

Problems propagate See Not measuring supplier performance

See Construction supply chains are loosely coupled

A large number of small companies might result in coordination issues and lack of learning from each other as new subcontractors are used on the next project

Via a standardised procedure for planning and sharing information independent on who joins the project

\section{See Construction supply chains are loosely coupled}

See Lack of coordination

See Not inhabiting a trustful climate

Wrong drawings and information might lead to reworks

Problems encountered already at the supplier site can develop to bigger problems further down the chain.
Via standardised procedures for sharing plans and information

Standardised metrics and measurement for assessing supplier performance and evaluate 


\subsection{Specifying the Purpose of this Study}

In order to develop a construction specific supply chain framework a starting point could be to 'scan' the market of existing frameworks. Fettke et al. (2005) scrutinized the existing frameworks for all kind of business modelling. They come up with some 30 business process frameworks that are more or less accepted among practitioners and academia. ARIS (Scheer 2000) and CIMOSA (ESPRIT 1993) are examples of business process frameworks that are common to date. While the number of existing business process frameworks could be considered rather large, the number of available frameworks for supply chain coordination and logistics is still scarce.

A framework could, according to Cohen and Roussel (2005), assists as a blueprint for guiding in the work of designing the improvement project. When it comes to frameworks for guiding the work of improving logistics and supply chain performance, the number of existing frameworks is small. Two frameworks that are globally known among academia and practitioners are the Value Reference Model (VRM) and the Supply Chain Operations Reference model (SCOR). Verdouw et al. (2010) present a number of different frameworks suitable for supply chain and logistics issues. However, they conclude that VRM and the SCOR model are the two most comprehensive frameworks suitable for logistics matters. While the SCOR model focus on the flow of material and information and takes the supply chain as starting point, the VRM focuses on the value adding chain of activities (from product research and design to market and sell etc.). The VRM model does not focus on the supply chain activities; focus is instead put on the manufacturing processes. The SCOR model on the other hand takes the supply chain in focus.

Cheng et al. (2010) concluded that using the Supply Chain Operations Reference (SCOR) model for modelling the flow of material and measuring supply chain performance could be of advantage for the construction industry. However, Johansson and Persson (2011) identified some discrepancies on how the construction industry is working and how the SCOR model is developed. For example, in construction, the factory is developed the same time as the end product. Other examples regard changing layouts (leads to changing inventory holding areas), one end product, one-of-a-kind nature, uncertainties, etc. These are aspects that are not treated in the SCOR model but affect pretty much everything in the construction supply chain.

Therefore, the SCOR model can be used as a basis for developing a construction supply chain framework. Reasons are (1) it is proven fruitful for improving profit margins in manufacturing industries (Bolstroff and Rosenbaum 2007). (2) It is well-recognised in other industries and encompasses well-defined definitions of metrics and processes. (3) Other authors (di Martinelly et al. 2009, Legnani 2011) has proven that the framework is adaptable to other industry contexts. Before specifying the purpose of this project further, it is necessary with a review of the SCOR model. 


\subsection{The Supply Chain Operations Reference Model}

All information presented in this subsection is collected from SCC (2013), if no other references are explicitly made. The SCOR model was first released in 1996, developed by two consultant companies to fill the need for a structured supply chain analysis tool. The SCOR model was mainly developed to improve the supply chain in the process and discrete manufacturing industries (henceforth entitled 'manufacturing companies'). Today, the SCOR model is owned by the non-profit organisation Supply Chain Council (SCC). SCC consists of nearly 1000 members and provides frameworks for e.g. the design process of a product.

In its essence, the SCOR model consists of two parts. The first part is about the work of conducting a 'change project' (called SCOR Project). It provides a step-by-step guidance on what to do; from identifying your supply chain to identify strategic requirements and how to improve. All necessary steps (called phases) to fulfil are presented in the Table 3 below. Each phase is thoroughly described in each sub-section below, except from the two phases of organising and implementing. Organising is about identifying the project team and available resources. The implementation phase describes how identified improvement suggestions could be implemented. The latter phase is often too companyspecific for making a general description of it. Phase V is therefore omitted.

Table 3 : The five phases in the SCOR model.

\begin{tabular}{|c|c|c|c|}
\hline Phase & Focus & Major Deliverables & Resolves \\
\hline - & Organise & $\begin{array}{l}\text { - Organisational support } \\
\text { structure }\end{array}$ & Who is the project team? \\
\hline I & Discover & $\begin{array}{l}\text { - Supply chain definition } \\
\text { - Supply chain priorities } \\
\text { - } \quad \text { Project charter }\end{array}$ & $\begin{array}{l}\text { What is the scope of the } \\
\text { project? }\end{array}$ \\
\hline II & Material & $\begin{array}{ll}\text { - } & \text { Geographic map } \\
\text { - } & \text { Thread diagram } \\
\text { - } & \text { Disconnect analysis }\end{array}$ & $\begin{array}{l}\text { Am I moving material } \\
\text { efficiently and effectively? }\end{array}$ \\
\hline III & Analyse & $\begin{array}{ll}\text { - } & \text { Scorecard } \\
\text { - } & \text { Benchmark } \\
\text { - } & \text { Competitive requirements }\end{array}$ & $\begin{array}{l}\text { How am I performing? } \\
\text { What are my strategic } \\
\text { requirements? }\end{array}$ \\
\hline IV & Work & $\begin{array}{ll}\text { - } & \text { Transaction analysis } \\
\text { - } & \text { Level } 3 \text {, level } 4 \text { processes } \\
\text { - } & \text { Best practices analysis }\end{array}$ & $\begin{array}{l}\text { Are my processes efficient } \\
\text { and effective? }\end{array}$ \\
\hline V & Implement & $\begin{array}{l}\text { - Opportunity analysis } \\
\text { - Project definition } \\
\text { - Deployment organisation }\end{array}$ & $\begin{array}{l}\text { What is the financial } \\
\text { opportunity? } \\
\text { How should I deploy? }\end{array}$ \\
\hline
\end{tabular}

The second part of the SCOR model is the SCOR Framework. This part consists of a number of predefined metrics, process-definitions, and best practices to use in phase II, III, and IV. The three elements of the SCOR Framework are interwoven described with 
the descriptions of phase II - IV below. A fictive company is also used for describing how all the phases work.

\subsubsection{Phase I - Discover the Opportunity}

The first phase in the SCOR model is to discover potential opportunities. In order to do that, a company needs to identify all supply chains and prioritise them. In line with the discussion made by Fisher (1997) and Lambert and Cooper (2000), different supply chains cannot be managed in the same manner and call for different priority.

A good start for identifying supply chains could be to map existing products with existing customers. According to SCC, a supply chain exists everywhere we have a connection between a customer and a product. Table 4 below shows that this fictive company has two products and four customers, resulting in five supply chains (each ' $\mathrm{X}$ ' below). To ease the work and reduce the number of supply chains, ' $X$ 's' that are similarly managed could be grouped. In Table 4 below it is identified that Product 1 to Customer 1 and 4 can be grouped and both Product 1 and 2 to Customer 2 can be grouped. In total this fictive company has identified three differently managed supply chains (X1, X2, and X3).

Table 4 : Identifying the supply chains.

\begin{tabular}{lcccc}
\hline & Customer 1 & Customer 2 & Customer 3 & Customer 4 \\
\hline Product 1 & $\mathrm{X} 1$ & $\mathrm{X} 2$ & & $\mathrm{X} 1$ \\
Product 2 & & $\mathrm{X} 2$ & $\mathrm{X} 3$ & \\
\hline
\end{tabular}

The next step is to prioritise the identified supply chains against important criteria. Examples of criteria could be revenue, gross margin, strategic importance, etc. Each criterion is weighted (if one criterion is more important than another) and each supply chain is then ranked according to these criteria. This results in an overall ranking of each supply chain and knowledge on which supply chains to focus the change-project on. In Table 5 below, each supply chain is ranked $(1-3)$ for each criterion ( 3 in total), where 1 is equal to low importance and 3 (or $n$ if $n$ criteria are used) for high importance. The rank of each criterion for each supply chain is then summarised and yields an overall ranking of the supply chains. A high ranking means a highly important supply chain.

Table 5 : Prioritising the supply chains.

\begin{tabular}{lcccc}
\hline & Ranking & $\begin{array}{c}\text { Criterion 1 } \\
\text { Weight: 33 \% }\end{array}$ & $\begin{array}{c}\text { Criterion 2 } \\
\text { Weight: 33 \% }\end{array}$ & $\begin{array}{c}\text { Criterion 3 } \\
\text { Weight: 33 \% }\end{array}$ \\
\hline Supply Chain 1 & 2.7 & 2 & 3 & 3 \\
Supply Chain 2 & 2.0 & 3 & 2 & 1 \\
Supply Chain 3 & 1.3 & 1 & 1 & 2 \\
\hline
\end{tabular}

\subsubsection{Phase II - Material Flows}

While Phase I results in what supply chains to focus on, the objective with Phase II is to map the flow of materials in those supply chains and identify problems. The maps can be 
either (or both) geographical or logical. The geographical maps might yield that key components in the production are to be sent from one corner of the earth to another. If the product is competing with competitors on time this might be hazardous.

For the logical maps, the SCOR Framework offers a set of predefined process definitions. These can be used to conceptually map the flow of materials and the activities accomplished in the supply chain. The standardisation means that a process means the same thing for all users. Each process is divided in a hierarchical manner in three levels. On the first level (the most aggregated level), there is five generic process types called Source, Make, Deliver, Plan, and Return. Level 1, according to Bolstroff and Rosenbaum (2007), defines the number of supply chains, how their performance is measured, and necessary competitive requirements. To gain a more detailed view of the flow of material it is necessary to map the flow with the level 2 processes. In level 2, processes are distinguished between type of production; Make-to-Stock, Make-to-Order, or Engineerto-Order. Level 1 and 2 are shown in Figure 6. In level 3, the activities in each level 2 process are listed. All level 1, 2 and 3 processes and activities are defined in the SCOR model.

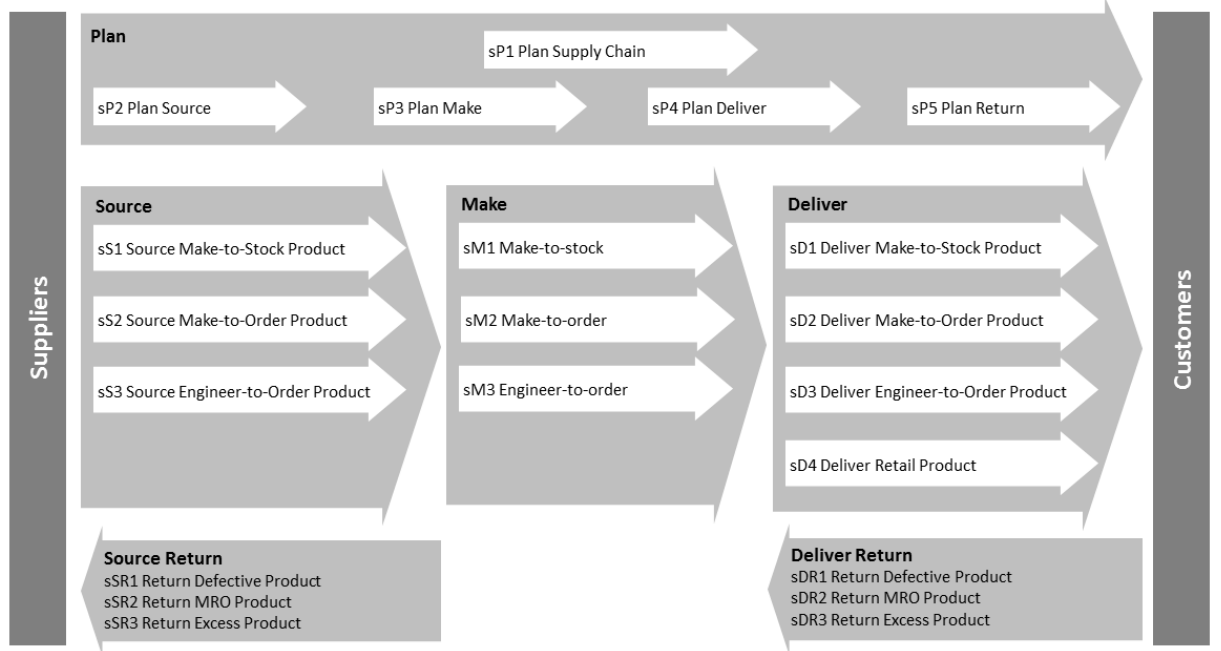

Figure 6 : The structure of the SCOR model in Level 1 and 2 processes.

The geographical map might reveal some more or less obvious deficiencies like long distances to transport time-critical components. The logical map is of importance to connect identified problems to a SCOR specific process. The identification of problems is nothing that easily can be translated into a what-to-do list. SCC suggests a brainstorming about root-causes to a certain problem. If a detected problem is that products are not delivered 'perfectly', the causes to this have to be identified. Causes could be that the goods were damaged on arrival, picked up late by the transporter, order was 'lost' in the order-system, etc. Each cause should then be connected to a certain SCOR process. For 
example, a late delivery of an on-shelf product is easily connected to the process SD1 Deliver Make-to-Stock Product.

The outcome of this phase is a map of the flow of materials and a list of problems and causes and which SCOR processes to focus on to remove the problems. The next step is to identify how these problems affect the performance of the supply chain. This step also results in a comparison of the company's supply chains performance with competitors supply chains.

\subsubsection{Phase III - Analyse the Supply Chains}

For performance measurement, the SCOR Framework offers a set of predefined metrics. These metrics are hierarchically structured in three levels. The most aggregated level is called Level 1 metrics $^{1}$, these metrics are also commonly known as Key Performance Indicators (KPIs). In total there are 11 KPI measurements that are divided into five strategic attributes (see Table 6). These attributes cannot be measured in itself, but they can be assessed through measurement of the associated KPIs.

Table 6 : Each level 1 metric and its corresponding attribute.

\begin{tabular}{|c|c|c|}
\hline & Attribute & Strategic metric (level 1) \\
\hline \multirow{3}{*}{ 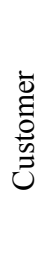 } & Reliability & RL.1.1 Perfect order fulfilment \\
\hline & Responsiveness & RS.1.1 Order fulfilment cycle time \\
\hline & Agility & $\begin{array}{l}\text { AG.1.1 Upside supply chain flexibility } \\
\text { AG.1.2 Upside supply chain adaptability } \\
\text { AG.1.3 Downside supply chain adaptability } \\
\text { AG.1.4 Overall value at risk (VaR) }\end{array}$ \\
\hline \multirow{2}{*}{ 苞 } & Cost & $\begin{array}{l}\text { CO.1.1 Total supply chain management cost } \\
\text { CO.1.2 Cost of goods sold }\end{array}$ \\
\hline & Assets & $\begin{array}{l}\text { AM.1.1 Cash-to-cash cycle time } \\
\text { AM.1.2 Return on supply chain fixed assets } \\
\text { AM.1.3 Return on working capital }\end{array}$ \\
\hline
\end{tabular}

The first thing to do when measuring the current performance is to identify which metrics are of relevance for which supply chain. The identified supply chains from Phase I are mapped against each attribute in Table 6. For each supply chain and attribute one attribute is chosen as a 'Superior' and two attributes are chosen as 'Advantage' and two attributes are selected as 'Parity'. This is visualised in for our fictive company. For the first supply chain it is identified that the most important thing to assess is reliability. This supply chain is competing against others based on e.g. the accuracy in delivery times. Agility and Cost aspects are also of importance but not as important as Reliability. The other two attributes are of less importance for supply chain 1 . This yields knowledge on what metrics to focus on for a certain supply chain.

\footnotetext{
${ }^{1}$ Not to be confused with level 1 processes. There is no logical connection between the levels in the process mapping and the performance metrics.
} 
The next thing to do is to collect data. This can be done automatically via e.g. IT-report systems or via manual work. For the attribute Reliability, the KPI to focus on is called Perfect Order Fulfilment. Figure 7 shows what Level 2 metrics Perfect Order Fulfilment consists of.

Table 7 : Competitive requirements for a supply chain.

\begin{tabular}{llll}
\hline Attribute & Supply Chain 1 & Supply Chain 2 & Supply Chain 3 \\
\hline Reliability & Superior & Parity & Parity \\
Responsiveness & Parity & Parity & Superior \\
Agility & Advantage & Advantage & Advantage \\
Cost & Advantage & Superior & Advantage \\
Assets & Parity & Advantage & Parity \\
\hline
\end{tabular}

\begin{tabular}{|c|c|}
\hline \multicolumn{2}{|c|}{ Hierarchical Metric Structure } \\
\hline Level 1 & RL.1.1 Perfect Order Fulfilment \\
\hline \multirow[t]{5}{*}{ Level 2} & RL. $2.1 \%$ of Orders Delivered in Full \\
\hline & RL.2.2 Delivery Performance to Customer Commit Date \\
\hline & RL.2.3 Documentation Accuracy \\
\hline & RL.2.4 Perfect Condition \\
\hline & 木 \\
\hline \multicolumn{2}{|r|}{ Orders Delivered Damage Free Conformance } \\
\hline
\end{tabular}

Figure 7 : Example of the Perfect Order Fulfilment metric.

When data have been gathered the information can be sent to SCC for benchmarking purposes. SCC provides information on how your company performs in comparison with competitors. Table 8 below depicts information about our fictive company and how they perform compared to others. For the Superior KPI Perfect Order Fulfilment it is obvious that they perform far from what other Superior competitors do, they have a gap of $87 \%$ to catch. However, for the Parity KPI Order Fulfilment Cycle Time they perform even better than other Parity competitors. To sum up, they have to pay a great deal of attention to the Perfect Order Fulfilment KPI but can reduce their efforts on the Order Fulfilment Cycle Time KPI. 
Table 8 : Benchmarking data for our fictive company.

\begin{tabular}{lccccc}
\hline $\begin{array}{l}\text { Strategic } \\
\text { Metrics }\end{array}$ & Actual & Parity & Advantage & Superior & $\begin{array}{c}\text { Requirement } \\
\text { gap }\end{array}$ \\
\hline $\begin{array}{l}\text { Perfect Order } \\
\text { Fulfilment }\end{array}$ & $50 \%$ & $74 \%$ & $81 \%$ & $88 \%$ & $38 \%$ \\
$\begin{array}{l}\text { Order } \\
\begin{array}{l}\text { Fulfilment } \\
\text { Cycle Time }\end{array}\end{array}$ & 9 days & 10 days & 6.5 days & 3 days & -1 day \\
\hline
\end{tabular}

\subsubsection{Phase IV - Work and Information Flows}

Phase I to III results in what supply chains we have and which to focus on. They also reveal in what activities are performed in the supply chains. Finally the three phases result in what problems we have and how our supply chains perform compared to competitors'. The fourth phase is about identifying improvement suggestions. The SCOR model offers a list of improvement suggestions for each process that other companies successfully have implemented. If the first steps result in that the company in question has to improve the planning process, the SCOR manual can be consulted to see what improvements are suggested in this process. (Surie and Wagner 2008)

For example, for the level 2 process Plan Supply Chain, SCOR offers five improvement suggestions, listed in Table 9. Each of these suggestions has their own definition and clarification in the SCOR manual. After selecting a proper best practice it has to be implemented. This is first done by mapping the future to-be state of the supply chain, with the best practice in mind. Afterwards, an important thing is to re-asses the performance, to see if the anticipated improvements become reality.

Table 9 : Best Practice suggestions for the Plan Supply Chain process.

\section{Best Practice}

All functions and organizations understand their impact on supply/demand balancing, including sales, marketing, product management, manufacturing, customer, suppliers, materials management, and product development

Change in the demand signal instantaneously 'reconfigures' the production and supply plans

Collaborative planning, forecasting, replenishment (CPFR)

Supply chain is designed to have supply flexibility equal to demand volatility

On-line visibility of all supply-chain demand requirements and resources, both currently available and committed (pegged)

\subsection{Research Objectives}

The phases presented in section 3.3 The Supply Chain Operations Reference Model above can be summarised into three elements: a Business Process Re-engineering (BPR) element, a Benchmarking element, and a Best Practice Analysis element. These elements and their constituting parts are all depicted in Figure 8. First, the current flow of material 
in the supply chain is mapped with predefined processes. Current performance of the supply chain is assessed after that. These two steps yield knowledge of where in the supply chain problems exist and what their magnitudes are, which can be used to compare with previous results, other projects, and competitors. The SCOR model offers a number of best practice suggestions for improving the problematic process. Finally, the wanted to-be state of the supply chain is mapped where problematic processes or activities are removed.

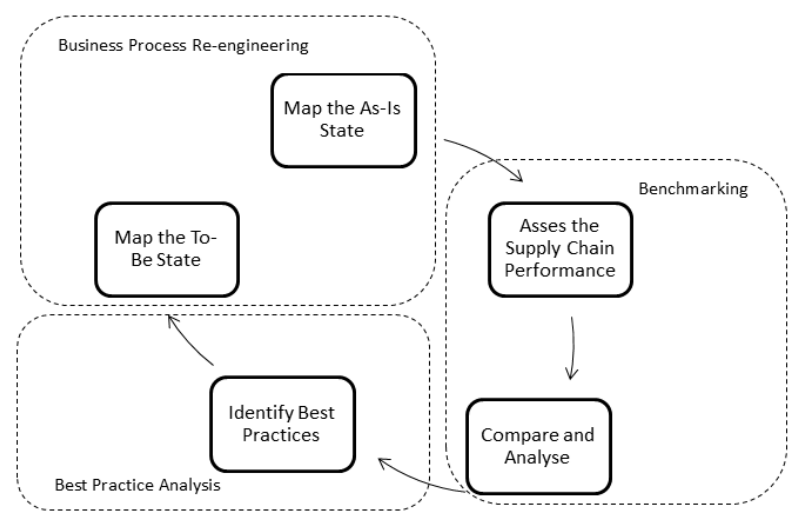

Figure 8 : The three constituting parts of the SCOR model.

Most of the procedures presented in the SCOR model and in Phases I to IV above are quite generic and works in almost any industrial setting. For example, identifying supply chains and prioritising them are not unique for the manufacturing industries. Not even the benchmarking procedure of how to measure, what to focus on, and how to compare is developed exclusively for the manufacturing industries. However, some discrepancies do exists. Take for example the predefined processes in the SCOR framework, presented in Figure 6. Are we talking about making a product in construction? Are sourcing in the manufacturing industries the same as in the construction industry? Do we plan construction projects as we plan in discrete manufacturing industries? Can best practices from the manufacturing industries also be used in the construction industry?

From the 2.2 Construction Supply Chain Management section it is evident that a construction supply chain differs in many aspects from a supply chain in the manufacturing industry (flow of resources, multiple companies, one end product, the factory is constructed at the same time as the end product, etc.). This calls for an adaption of the SCOR model to the characteristics of the construction industry when it comes to the definition of the processes and metrics. This includes a creation of a benchmarking system for the construction industry with a database of best practices.

The purpose with the study (as presented in section 1. Introduction): to develop a framework for process mapping and performance measurement in construction supply chains (based on the SCOR model as specified in section 3.2 Specifying the Purpose of this Study) can after this discussion be specified to: to adapt the SCOR model to the 
characteristics of the construction industry. The adapted version of the SCOR model will be named the BSCOR model (Builder's SCOR model). It is not named CSCOR (construction SCOR model) for not confusing it with the SCC trademarked CCOR model. The suffix 'model' is also kept, even if both the SCOR model and the BSCOR model are perceived to be 'frameworks'. In order to adapt the SCOR model (by which I mean the processes and the metrics) these objectives are considered (bear in mind the demarcations made in 1.5 Demarcations):

Objective 1. Adapt the SCOR model's Deliver process to the characteristics of the construction industry.

Objective 2. Adapt the SCOR model's Source processes to the characteristics of the construction industry.

Objective 3. Adapt the SCOR model's Make processes to the characteristics of the construction industry.

Objective 4. Adapt the SCOR model's Plan processes to the characteristics of the construction industry.

All these objectives concern the adaption of the Level 1 processes in the SCOR model. Except from identifying necessary changes in Level 1 the objectives also concern identifying necessary changes in Level 2 and 3 plus alterations to the concerning metrics. An overall objective with this thesis is also to present important insights into how logistics is handled in construction. This is done by assessing logistics performance and identifying logistical problems. These insights do not help in fulfilling the objectives with this study but are rather results of the work with fulfilling objective 1 to 4 .

Regarding the Best Practice element in the SCOR model, it is evident that best practices from the manufacturing industry cannot be transferred straight off to construction industry (cf. Green et al. 2005). However, the time and the number of construction projects needed to create a reliable and extensive database with best practices is not enough in this project. This topic is therefore omitted in this project and left for a future study. 


\section{Research Design and Method}

The content presented in this section aims to describe the overall research design and motivate why the chosen research methods were selected. It also aims to describe how the method in each paper was conducted. To sum-up, the author's statement, where the study is presented in a bigger context, is given together with a discussion on research validity.

\subsection{Research Design}

The work with adapting the SCOR model started in early 2008 by applying it to a construction supplier called Inwall (see Nordqvist 2008). This supplier delivers bathroom modules to Swedish construction companies. The results indicated that the model had to be adapted to the construction industry. In late 2008 a case at a Swedish construction site (called Tornet) verified the need for adaption (Bengtsson and Gustad 2008). Figure 9 depicts how the experience from these two cases (where the author of this thesis did not participate in the research) laid the ground for the study presented in this thesis.

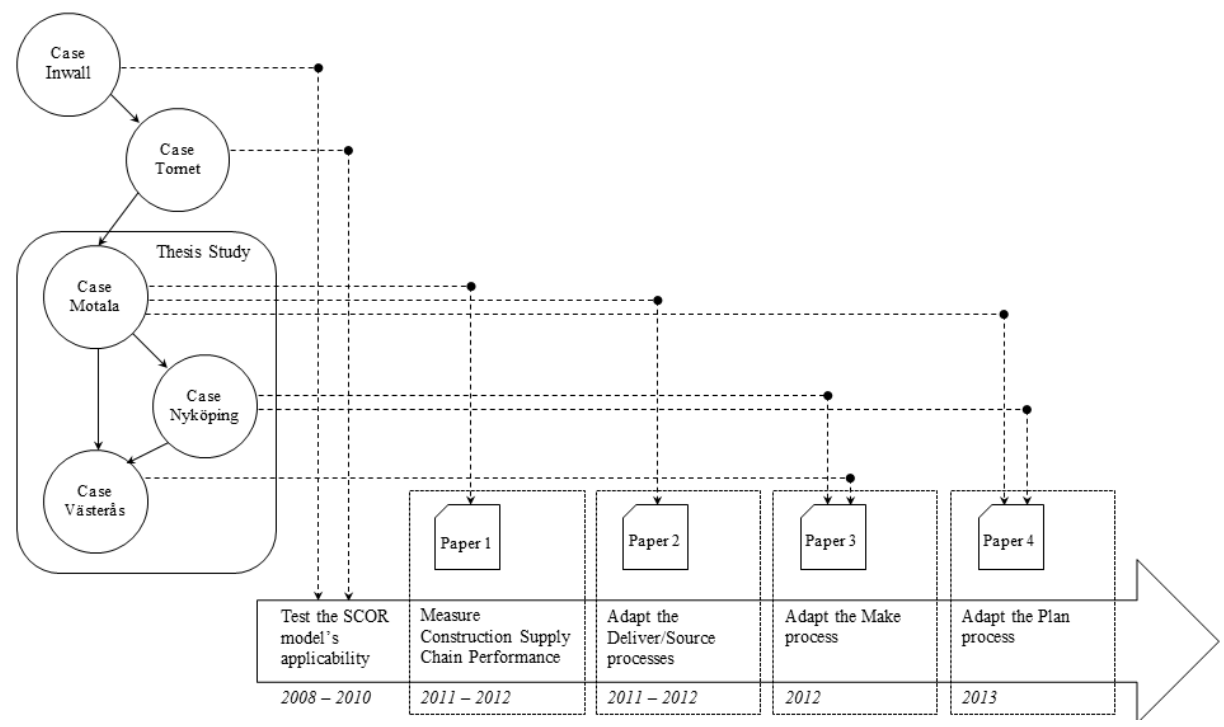

Figure 9 : The research process with outputs.

Figure 9 also shows how the three cases in this thesis are connected and what outcomes they had (in terms of experience to succeeding cases and papers). The design of the project has followed the design of the SCOR model, depicted in Figure 10. In total five cases over a four-year period were studied. Figure 10 also shows how each case connects 
to the SCOR model and what part of the SCOR model each paper considers. Paper 1 is not included in Figure 10 as it does not consider the adaption of the SCOR model. As discussed in section 1.5 Demarcations, the Deliver (from site to customers) and Return processes are not included in this study.

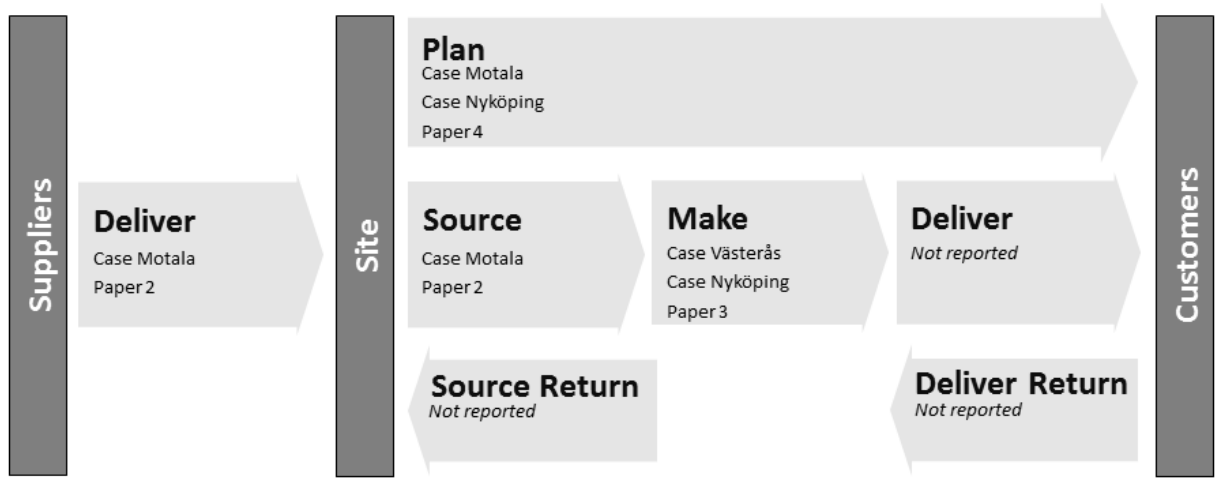

Figure 10 : The general structure of the SCOR model.

The actual adaptions of the model started in 2010 in the Case Motala, where the first processes in the SCOR model (Deliver from the suppliers to the Source process at the construction site) were studied at a Swedish construction site in the municipality of Motala. These two processes describe the material delivery activities at the suppliers and the procurement of construction materials process on-site. The results proposed what in these two processes that need to be adapted. The author of this thesis was involved in the data gathering process during this stage but enrolled as a $\mathrm{PhD}$ student first in the analysis phase in this stage. The next phase in the research design regards the Make process in the SCOR model. The construction processes and its logistics activities were studied at two case studies in the towns of Nyköping and Västerås. These two cases yielded necessary input on which changes to the Make process were deemed necessary. Finally, input from both the Motala case in 2010 and the Nyköping case in 2011 were used to identify how the Plan process should look like.

\subsection{Choice of Method}

Reasons for selecting case study research as the main method in this project are several.

(1) It is a proper method when you want to observe the phenomenon in its natural setting (Yin 2009). Instead of deductive reasoning, unaware of the construction context, on how the model should look like, one way could be to observe the context first and then come to the conclusions (the latter approach was employed in this thesis work). (2) With other methods it could be difficult to see why something is happening. With survey for example, dependencies between situations and causes and effects would not be observed. With a case study approach, when something is observed on-site, follow-up questions can be asked immediately, this is not possible with a survey. Experiments are not applicable for this kind of study. It is impossible to find a 'significant' number of construction 
projects that have exactly the same settings. (3) As the author is not experienced in construction a first step is to get an understanding of the construction industry by being on-site and make observations.

The very nature of this study would be of a explorative kind, according to the terminology of Voss et al. (2002). This means that information is gathered in order to shape an initial idea or theory for the next step, the theory building phase. Voss et al. (2002) suggests indepth case studies and unfocused, longitudinal field studies as proper research structures. The in-depth and longitudinal cases decrease the risk to collect temporarily and biased information. The proposal of an unfocused case study minimises the risk of a priori preconceptions of what to look for. In this study, three cases are observed in-depth during a time period of six month each.

The cases in this thesis were selected according to three criteria. (1) The projects should be in the framework supplement phase as this is the phase where the most materials are delivered to the site. It is also this phase where most subcontractors enter the project leading to a large number of craftsmen and organisations sharing the same site. (2) The budgeted cost should be in the interval of $€ 1-10$ million, which is considered to be a medium-sized project. According to the contact person at the case company (involved in all three projects) larger projects seldom experience the logistic problems as the medium sized do. This is not entirely true, they do experience problems, but not to the same extent as mid-sized projects. This could be due to the fact that the planners have to think about most logistic aspects on beforehand in larger projects, as there is no room for failure. In medium-sized projects the mentality is often that these problems are solved as time goes along. Smaller projects cannot justify the cost with implementing such a comprehensive framework, and therefore the framework aims to assist medium-sized projects. (3) Finally, the sites should be within geographical proximity for the researcher. This enables the researcher to quickly move from one place to another when something of interest for the researcher happens. Another aspect considered when selecting the cases was that the site manager and the construction supervisors should be open-minded in assisting the researcher. This facilitated the work with gathering necessary data plus that the openness attitude is propagated to the craftsmen.

Each subsection in section 4.3 The Research Process below will describe how data were gathered. Overall, the main data gathering methods utilized during all three cases are direct observations (both by the researcher and by master thesis students) and semistructured interviews with focus on identifying necessary adaptions to the SCOR model. The interviews have served as a possibility to verify observations but also to get insights in what to observe.

\subsection{The Research Process}

The following sub-sections will describe the data gathering method for each paper. In total, the study resulted in four written papers. Whereof one has been published, two have presented at conferences, and one is a working paper. 


\subsubsection{Paper 1 - Assessing Construction Logistics Performance}

As stated earlier, the purpose with this study contains four research objectives regarding adapting the SCOR model. It also contains one overall objective about adding to the knowledge about logistics in the construction industry. The first paper reports on the latter one. Both Paper 1 and 2 are findings from the same case study (Case Motala, see Figure 9). Paper 1 aims to assess the perfect order fulfilment (POF) value for the suppliers delivering to the construction site and the source cycle time (SCT) and is published in the journal Production Planning and Control (Thunberg and Persson 2013b).

In order to assess the POF, the delivery must be of the right amount delivered at the right time at the right place, and with the right documentation. Unit of analysis for measuring POF are the construction suppliers and their work with delivering materials to site. To gather necessary data two methods were used, site observation and survey. The direct observations were done in order to verify if the delivery was 'perfect'. After discussion with the case company it was decided that all kinds of material should be studied. For each incoming delivery, a form was used to note date, time, item delivered, quantity (number of pallets), received documents, delivery place, and condition. After analysing the actual delivery with the order documents it could be determined if the items were perfectly delivered. Later on, an aggregated value for the POF could be calculated according to the SCOR model's definition. In order to verify the findings but also to extend the set of data with more observations (as the researcher could not observe all incoming deliveries) the responsible craftsmen for managing incoming deliveries were asked to fill out a form after each delivery. The form consisted of the same observation points as for the researcher. However, some samples were taken to check that the craftsmen performed the tracking in the same manner as the researcher. Except from this quantitative research, notable qualitative insights also were gathered on how e.g. a late delivery affects the construction site.

In this study the SCT measures the construction site responsiveness and how much time is spent on the non-value adding activities of receiving materials. Unit of analysis for measuring SCT is the construction site itself and the daily work with managing incoming deliveries. SCT is measured via assessing the time spent on scheduling the delivery, verify the delivery, transfer the materials, and authorise payment to suppliers. To begin with, an as-is map had to be created in order to analyse the activities conducted by the craftsmen. This was also the basis for the adaptations suggested in Paper 2. A regular stopwatch was used to measure the time spent on each activity. The measure of the SCT was assessed according to the SCOR model's definition of the SCT calculation. The SCT was also verified by interviewing the site manager and the craftsmen. In this way they could verify if the times were considered representative or not.

The measurement of the POF and SCT metrics was stored in an Excel file for future analysis. In this file, the two metrics could be displayed on different aggregation levels. The metrics could be presented on a project level, supplier level, and a transporter level. In this way it could be analysed if a certain supplier outperformed other suppliers. It could also be analysed if a certain transporter was to blame for any delivery failures. The Excel 
file also showed what type of failure caused a low POF. For those data-points where information was missing, a sensitivity analysis was done. This yielded an interval wherein the result of the POF metric was situated. Finally, the POF value was compared with information from the SCC to see how the construction suppliers performed in comparison with other types of suppliers.

\subsubsection{Paper 2 - The First Step in Creating the BSCOR Model}

While Paper 1 presents the results concerning the overall objective of this study, Paper 2 presents the study concerning the first and second research objectives. It is about identifying necessary adaptions to the SCOR model in the interface between the suppliers and the construction site (the Deliver and Source processes). Both Paper 1 and 2 are based on the same case study, so the method used in Paper 2 is the same as in Paper 1. The findings in Paper 2 were presented at the NOFOMA conference and published in the NOFOMA proceedings (Persson and Thunberg 2012). The observations during the process to calculate the POF and SCT values resulted in insights on how the model should look like. Unit of analysis is the construction site itself and the daily work with managing incoming deliveries. Data gathered through direct observations were verified via informal meetings. During the observations valuable information was gathered that were analysed and later on validated by the site manager, supervisor, and the craftsmen through informal meetings and interviews. In this case, the meetings and interviews assisted as a way to achieve validation.

The data gathered in Paper 2 was noted in a case study diary for future analysis. This notes contained information of what activities were performed and why together with time and date, etc. This information was then classified into 'activities'. In this manner, a conceptual map of what the craftsmen do in a certain process (like the sourcing process) could be drawn. This map was then compared with the activities and structure emphasised in the SCOR model. This brought forth similarities and differences between how processes were performed on the construction site and how the SCOR model expects it to be performed. In order to verify the findings, results were shown to the site manager. If the activities were 'abnormal', revisions had to be done according to the information from the site manager. The encountered similarities and differences between the SCOR model and the activities on-site were suggested as adaptions necessary to include in the BSCOR model.

\subsubsection{Paper 3 - Developing the Build Process}

Paper 3 is a working paper (Thunberg and Persson 2012). The paper presents what changes to the SCOR model are necessary in the production process (called Make in the SCOR model). The conclusions are drawn based on two parallel case studies conducted on two construction sites situated in the two Swedish towns Västerås and Nyköping, respectively (see Figure 9). In this case study, master students were used to collect data in two embedded units (Västerås and Nyköping). Unit of analysis is also here the construction site and the craftsmen's work with building the house. The methods used were more or less the same as in Paper 2. Direct observations and interviews were 
performed by the master students and resulted in what changes to the Make processes were deemed necessary.

The data gathered in Paper 3 was noted in two case study diaries (one for each case) for future analysis. This notes contained information of what activities were performed and why together with time and date, etc. The two cases were then compared to identify similarities. This information was then compared with the SCOR model to demonstrate similarities and differences. As in Paper 2, the differences between the SCOR model and how the construction site performed the activities were suggested as inclusion in the BSCOR model.

\subsubsection{Paper 4 - Coordinated Supply Chain Planning}

The last paper is based on further processing of the two studies in Västerås and Motala (see Figure 9), where the Planning process in the SCOR model has been scrutinised. Unit of analysis is also here the construction site and the work with planning the construction. The method used in this paper is two-phased. First, problem areas found in the literature regarding planning are compared with problem areas found in the two case studies regarding the planning process. This study is therefore more of a retrospective nature, where the two previous studies are re-visited and analysed. The identified problem areas are summed up in a 'gross-list'. The second phase consisted of scrutinising the SCOR Plan process to see how it can help in overcoming the identified problem areas. This deductive reasoning process led to the conclusions on what changes to the SCOR model are deemed necessary in order to mitigate these problem areas. The findings were presented at the $7^{\text {th }}$ Nordic Conference on Construction Economics and Organization (Thunberg et al. 2013) and the paper was one out of six papers nominated to the 'Best Paper Award'.

\subsection{Validation and Reliability}

One of the things that could affect the reliability of this thesis is the fact that master students have been used to do observations and data gathering. To increase the reliability regular meetings have been held, where experience from the students are gathered. Reliability has also been achieved via careful instructions of what to do and how to do it. On the other hand, the use of master students (or multiple investigators as Eisenhardt, 1989 , would call it) could serve as validation and be of advantage. As new eyes observe a phenomenon they can both verify the findings plus give new experiences and knowledge on the phenomenon. Eisenhardt (1989) describes that using multiple investigators can lead to that insights either are validated (if the findings are convergent) or that they need to be re-shaped if they are divergent.

Validity is often categorised as construct, internal, and external (Yin 2009). It is difficult to verify if construct validity is achieved in this thesis. Supply chain performance could mean many things. Were the right measurement and the right level of aggregation chosen? This cannot easily be answered as another performance metric could be chosen for measuring other types of supply chain performance. A 'perfect' delivery is here 
considered to be on-time, in correct amount, with the right documents, on the right place, and in the right condition. Construct validity can then be considered to be achieved as the $P O F$ metric does measure these elements. Internal validity in this study is achieved through always analysing why something is happening. This has been done via interviews and meetings with craftsmen and managers. They could then verify whether studied behaviour was common or not and describe why they occur. External validity is achieved by testing the previous case findings on succeeding cases. Eisenhardt (1989) also elaborates on the idea of having cases that contextually differ. If the findings are valid for both cases it results in even higher validity. In this study, all cases have about the same contextual settings (see 4.1 Research Design), which can be disadvantageous. However, since the framework is still in its developing phase, literal replication (Yin 2009) is deemed suitable.

\subsection{Author's Statement}

The main stakeholder in this project is the research centre Brains and Bricks $\left(\mathrm{B}^{2}\right)$ with the Swedish construction company Peab in the forefront. $\mathrm{B}^{2}$ is a research-collaboration between Linköping University, the municipality of Katrineholm, and Peab. All cases in this project are conducted on construction sites run by Peab.

The first study (the Motala case) was made by the thesis author as a master thesis work, together with Glenn Gyllin, with Maria Johansson and Fredrik Persson as supervisors (Gyllin and Thunberg 2010). An early version of the findings was presented at Plan's forskning och tillämpningskonferens 2011 (Thunberg 2011) and has been revised into two separate papers (Paper 1 and 2) with the author's co-supervisor as the main author in one of them (Persson and Thunberg 2012, Thunberg and Persson 2013b).

The second study (the Västerås and Nyköping cases) was performed by the thesis author as part of the $\mathrm{PhD}$ project. The co-supervisor, the author, and Peab designed the cases but three master students performed the actual data collection as two master thesis projects (Javalds and Lokander 2012, Johansson 2012). These projects resulted in two papers (Paper 3 and 4) where the author and the co-supervisor took equal part in compiling the necessary changes to the production process in the SCOR model, presented in Paper 3 (Thunberg and Persson 2012). In paper 4, the main supervisor (Martin Rudberg) took part in compiling the deemed changes to the Planning process, even though the thesis author was responsible for the entire compilation process (Thunberg et al. 2013).

Paper 2 to 4 have also been summarised in a paper presented at the ARCOM conference 2013 where the current version of the adapted framework also was presented (Thunberg and Persson 2013a). This paper is not included in the thesis but serves as the basis for developing the introductory chapters. 


\section{Summary of Papers}

This chapter aims to briefly summarize the four papers contributing to this thesis. The summary is organised by first describing the background with corresponding scientific gap and purpose. It concludes with a description of the findings and what contribution the paper makes. A general contribution as such is given in section 7. Conclusions.

\subsection{Summary of Paper 1}

The construction industry faces many different concerns as described in section 2.3 Construction Logistic Issues. It is stated that the many problems have a negative effect on the construction performance and the ability to deliver products in line with the customer's requirements. Many authors state that logistics and Supply Chain Management (SCM) can positively affect the negative trend. In order to assess how well logistics and SCM principles have been utilised, it is of great concern to assess the current state of the industry's logistics situation. It is also of interest to present a measurement system that can be used across the industry to assess and evaluate logistics improvement suggestions.

However, a great deal of the current literature on the matter of assessing project performance regards the output, how well the end product (e.g. the house) corresponds to the customer's perception on quality, time, and cost. This is of course an extremely important perspective to evaluate; without satisfied customers, no business. Nevertheless, as many authors report on, much of the problems encountered on-site stem from mistakes earlier in the supply chain. Therefore, this paper sets out to assess the input, the logistics performance that the construction site will face.

The purpose is therefore to find suggestions for improving construction logistics using the SCOR model's predefined performance metrics related to the delivery process at the supplier and the sourcing process at the construction site via empirical assessment. The assessment is performed via a single case study at a construction site located in the Swedish town Motala. The research questions can be expressed as follows:

RQ1. How reliable are construction suppliers in terms of Perfect Order Fulfilment (POF) at the construction site?

RQ2. How responsive is the goods reception process in terms of Source Cycle Time (SCT) and Cost to Source (CS) at the construction site? 
RQ3. What suggestions can be made to improve reliability and responsiveness at the construction site?

The findings show that the answer to RQ1 is a POF value of $38 \%$. A POF of about $38 \%$ can be considered relatively low, if compared with benchmarking data from SCC. 134 minutes and EUR 249 are the answers to RQ2. This means that about 134 minutes is spent on each incoming delivery by the craftsmen on the non-value adding activity of receiving the materials, to a cost of about EUR 249. Finally, the answer to RQ3 is summarized in five improvement suggestions concerning communication, predefined material allocation, supplier performance assessment, delivery verification and notification, and use of the SCOR model.

This paper does not contribute to fulfil any of the four objectives. However, it does contribute on the overall objective, to present an insight in the logistic status in the industry. It is of course impossible to draw general conclusions about the industry from just one case study. Despite this lack of generalisation, the study does fill a gap. The existing literature on assessing supplier performance is scare. Paper 1 can therefore be seen as a starting point and be used as a base line for future performance assessment (in terms of POF and SCT). For practitioners, the findings from this paper show how the performance of suppliers could be measured.

\subsection{Summary of Paper 2}

This paper is the first one of three that has the focus on adapting the SCOR model to the characteristics of the construction industry. It takes the interface between the suppliers and the construction site itself as a focus. It all started in 2008 when two case studies showed that construction industry could benefit from using such a comprehensive framework as the SCOR model. However, the two case studies also showed that the SCOR model is not sufficient as it is. The construction industry differs in many regards from e.g. the manufacturing industry. In the construction industry, the factory is for example developed at the same time as the end product, delivery of resources, etc. The studies showed that the SCOR model has to be adjusted to how the construction industry works, by considering contextual factors.

Investigating current literature on frameworks in the construction industry reveals that they are few and mostly lack in considering contextual factors. The purpose with this paper is therefore to introduce an adapted version of the SCOR (Supply Chain Operations and Reference) model to improve construction logistics by mapping and measuring supply chain activities and performance. Sub-processes and metrics related to the Deliver and Source processes in the SCOR model that are in need of changes to adapt SCOR to the construction industry settings are identified. To fulfil this purpose the following three research questions are investigated in this paper via the same single case study as presented in Paper 1. 
RQ1. Considering the construction site, are there any new level 2 and 3 processes that need to be added to the SCOR model to better map the construction site activities?

RQ2. Considering the Deliver and Source processes at the construction site, which level 3 processes are i) directly suited for mapping, ii) needs adaptation to the construction setting and iii) are not suited at all for mapping?

RQ3. Considering the Deliver and Source processes at the construction site, which metrics are i) directly suited for measurements, ii) needs adaptation to the construction setting and iii) are not suited at all for measurements?

Evidence from this study indicates that notification of deliveries from the supplier to the construction site is deemed necessary. Therefore, RQ1 is answered by adding a level 3 process at the supplier side regarding notifying the construction site. The study also revealed that the verification of incoming deliveries work quite differently from the manufacturing industry. RQ1 is thus also answered by the addition of a second verification process at the construction site. These changes all regard level 3 in the SCOR model. On level 2, new processes regard how materials are sourced. The SCOR model separates the sourcing process in the manufacturing industry based on if the end product is of Make-to-Stock, Make-to-Order, or Engineer-to-Order character. This is not considered necessary in on-site construction projects, as the end product is often of an Engineer-to-Order character. However, what is necessary is to separate the sourcing process based on who is sourcing and if materials or resources are sourced. Consequently, RQ1 is also answered by the addition of the level 2 processes Source construction materials, Source resources, and Source subcontractor materials. RQ2 is answered for instance by removing a level 3 process at the supplier side regarding installation of the materials, as all materials are installed either by the main- or the subcontractors. The original verification process in the SCOR model is also revised according to the aforementioned discussion, this also contributes in answering RQ2. Finally, RQ3 is answered by the discussion of adding the Notifying in time metric to the calculation of the Perfect Order Fulfilment metric.

This paper contributes in fulfilling the thesis Objective 1: "Adapt the SCOR model's Deliver process to the characteristics of the construction industry" and Objective 2: "Adapt the SCOR model's Source processes to the characteristics of the construction industry. However, it is clear that it also touches the overall objective on presenting insights in the logistical status in the industry. For example through identifying similarities and differences between the manufacturing industry and construction industry. After this paper, we now know how the SCOR model has to be adapted in the interface between the supplier and the construction site.

\subsection{Summary of Paper 3}

In this paper, the focus is on adapting the SCOR model's Make process and is based on two case studies. The literature reveals a lack of interest in creating a comprehensive 
framework that also incorporates the activities performed on-site during the construction phase. This working paper aims to adapt the SCOR model's Make process and to develop the BSCOR model's Build process. The objective with this paper is to identify which processes and metrics are deemed necessary, and which are not, for inclusion in the BSCOR model's Build process.

Findings from the paper indicate that the separation in subcontractor and main contractor sourcing processes suggested in paper 2 also are relevant for the construction process. Therefore, it is suggested that the BSCOR model should separate the construction work on level 2 based on who is performing the work. A great deal of changes on level 3 is also presented. They are all based on the Swedish Construction Federation's 'Nybyggnadslista' (Swedish for: List of New Construction Processes), see (BI 1999). The biggest change is that the SCOR level 3 process Produce and Test is removed. Instead it is replaced with the level 3 processes Site Work, Foundation, Framing, Façade, Framework Supplement, Interior Work, and Installations Work. The activity of testing is instead incorporated in the definition of each level 3 activity.

It is evident that the Build process incorporates few logistics issues (which is contrasting with a priori expectations). Instead, the logistics problems encountered on-site during this phase are the results of problems from upstream in the supply chain. The contributions of this working paper regard the adaption of the Make process in the SCOR model (i.e. Research Objective 3). In order to create a comprehensive framework, the Make process and its logistics activities have to be adapted. However, this paper also reveals the fact that the Handover process incorporates few logistics activities and will therefore not be adapted in this thesis. Regarding returns, the paper also shows that these are absent in the construction industry, in terms of how the SCOR model defines returns. Wastes, which could be considered as a form of return, are often delivered to special companies that recycle or use the material for fuel in combined power and heating plants. Resources that are rented are being returned to the renting companies. This does not correspond to the definition of Return in the SCOR model, where returns are made of defective, MRO (Maintenance Repair and Overhaul), and excess material. None of these types of returns have been found in any of the construction projects that have been studied. A discussion on the topic about the BSCOR model's completeness is presented in section 7.2 Purpose Reflection and Contributions.

\subsection{Summary of Paper 4}

All activities on-site, in the supply chain, and before the construction project are preceded by an extensive planning process. According to current literature the planning process is often divided into pre-construction planning and on-site planning. It is also stated in the literature that most focus have been directed towards the ability to create advanced scheduling techniques. The importance of overcoming the common planning problems that exist has not received the same attention as the scheduling techniques. The problems that exist in the planning phase often concern the lack of integrating subcontractors in the 
planning process. Current literature that concerns this topic is good at pointing out this problem but not in showing how the subcontractors should be integrated.

The main purpose with this paper is to analyse how supply chain planning in construction can be better coordinated, both concerning the supply chain as such and concerning activities on-site. To fulfil this purpose, these two research questions are answered:

RQ1. Which are the most common planning problems identified in the construction supply chain and on the construction site, respectively?

RQ2. Can the SCOR Plan process facilitate the implementation of effective supply chain planning principles in the construction industry?

Regarding the answer to RQ1, it all comes down to coordination and integration; coordinating work among members in the supply chain and integrating the subcontractors in the planning process. Many problems (listed in Table 1 in section 2.3.2 Planning in Construction) and their effect on the construction performance can be avoided if the integration issue is solved. The suggestion on how the subcontractors should be integrated, presented in this paper, represents the answer to RQ2. The suggestion lies in separating the planning process based on if it is the main- or the subcontractor that makes the plan. A balancing activity is added in the planning process, where the plans from the different actors are balanced. The balancing activity is also added in the process for planning the sourcing activities and the process for planning the production itself. In this way, the different companies first take their own prerequisites into consideration. The project prerequisites and the other contractors' plans are considered altogether later on, during the balancing process.

This paper contributes mostly to the thesis's Objective 4: "Adapt the SCOR model's Plan processes to the characteristics of the construction industry". Changes suggested on how the construction adapted planning process should look like correspond with this objective. However, it also reports on a number of problems when it comes to planning logistic activities. It therefore also contributes on fulfilling the overall objective, to present a logistical status in the construction industry. Contribution to the construction industry regards the suggestions on how the coordination and integration of subcontractors should be designed. 


\section{Developing a Construction Supply Chain Framework}

As pointed out a couple of times in this thesis, the SCOR model could be a suitable framework to map and measure construction supply chain performance. However, as also stated earlier, adaption of the SCOR model is necessary. The foregoing chapter summarised the four papers contributing to this thesis. Three of them (Paper 2-4) describe how the processes Deliver, Source, Make, and Plan have been adapted, respectively. This section describes how the framework as such was created. First, motivations to suggested changes and the underlying principles with the BSCOR model are given. Finally, each process is described in more detail and a discussion on how to implement the BSCOR model is given.

\subsection{The Underlying Principles with the BSCOR Model}

The result of the work to adapt the SCOR model to a construction industry setting is called the Builder's SCOR model (BSCOR). The BSCOR model retains the basic structure of the SCOR model and keeps the processes and metrics from the SCOR model intact (except from the installation of materials in the Deliver processes). This means that the SCOR model can be used by the suppliers up-stream in the supply chain. The BSCOR model is used by the contractors on-site. In other words, the BSCOR model is an "addon" to the SCOR model, with adapted processes and metrics. In this way, the SCOR model and the BSCOR model can be used to map the supply chain from suppliers of construction materials to, and on, the actual construction site.

Before describing each element in the BSCOR model, it is necessary to describe the underlying principles to the suggested adjustments. In order to do that it is required that an overview of the framework is given. The flow of materials is on level 1 modelled with the processes Builder's Deliver, Builder's Source, Builder's Build, Builder's Handover, and Builder's Return. The Builder's Plan process is used to model the planning procedures. The level 1 processes are all depicted in Figure 11. The dashed processes are excluded in this study. The Builder's Deliver process is the connection between the SCOR model (used by the suppliers) and the BSCOR model (used by the contractors); this is further described in section 6.2 The BSCOR Model. 


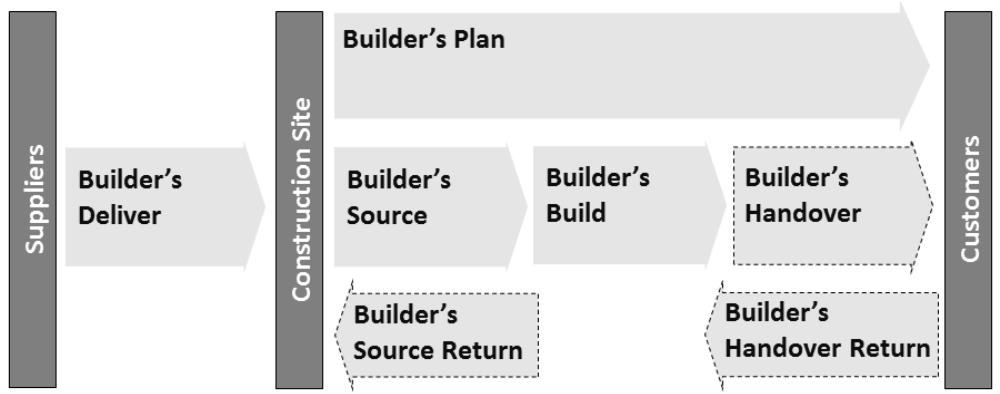

Figure 11 : The BSCOR model's level 1 processes.

The BSCOR model is created based on two basic principles. First, the material flow is divided into two separate flows depending on who ordered the construction material; the contractor or the subcontractors. The main contractor, which has an overall perspective of the project and of the site itself, plans the incoming deliveries based on that overall perspective. The subcontractors lack the comprehensive view and see only to their part of the project. In the study presented in Paper 2 it was clear that this separation of material flows caused problems with deliveries at the site with trucks forced to share unloading areas and waiting for their turn for resources such as wheel loaders used for unloading materials. In the BSCOR model, the two material flows are kept separated in order to identify the flows and thereby highlight the need for coordination.

The second principle is the identification of deliveries of temporary materials that are used for a period of time and then returned. Typically, scaffolding is such a material that is used on-site, stored on-site, and returned after the project is completed. In the BSCOR model, this type of delivery is called a delivery of resources and includes also wheel loaders and cranes. Figure 12 depicts each level 1 process' level 2 processes and how the two basic principles discussed above pervades the framework. In level 2, the Plan process remains of the structure in the SCOR model with a planning process for the sourcing, building, and handover process.

\subsection{The BSCOR Model}

The BSCOR model consists of six processes: the Builder's Deliver, Plan, Source, Build, Handover, and Return (see Figure 12). The Builder's Deliver process is the link between the SCOR model and the BSCOR model. The reason for this is that the SCOR model can be used upstream as it is today (except from the inclusion of the Builder's Deliver process) and the BSCOR model is used downstream. The Builder's Deliver process is a component that sets out to model the activities performed by the supplier side to deliver the materials to the construction site. Whereas the Builder's Plan, Source, and Build processes are described in more detail below the Handover and Return are omitted, as described in the demarcation section in the introduction. For simplicity, henceforth the Builder's Plan, Source, and Build processes are denoted bP, bS, and bB, respectively. The prefix ' $b$ ' means that we are talking about the BSCOR model, an 's' refers to the SCOR 
model's processes. Each level 2 and 3 process has its unique identification number. Like, bP6 refers to the Plan Source process and bP6.1 to the Identify, Prioritize and Aggregate Product Requirements. Each subsection below also contains descriptions of the level 3 processes.

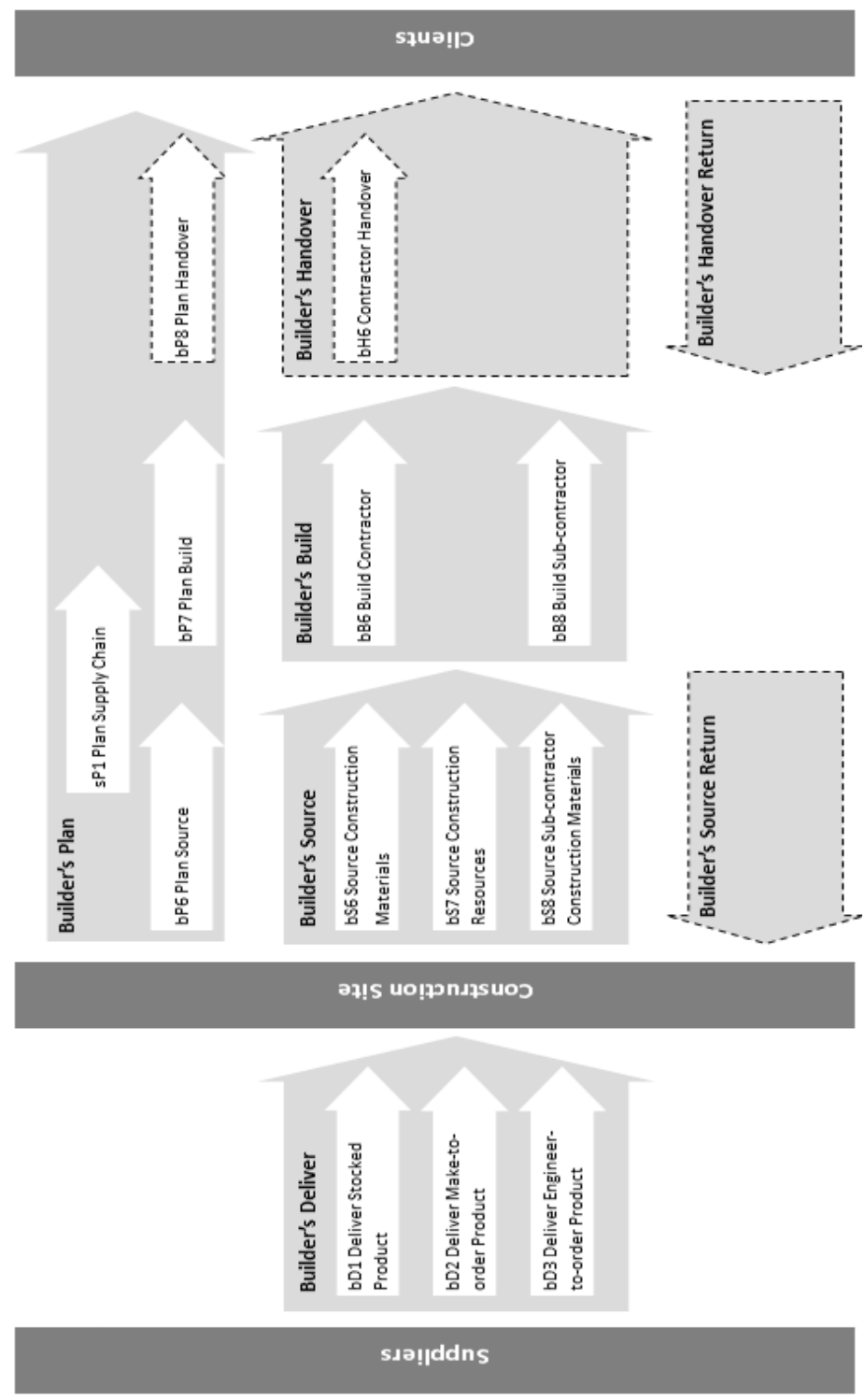

Figure 12 : The BSCOR model's Level 2 processes. 


\subsubsection{The Plan Process}

The plan process in the BSCOR model consists of three level 2 processes: Plan Source (bP6), Plan Build (bP7), and Plan Handover (bP8), see Figure 12. Originally, the SCOR model includes a process called Plan Supply Chain (sP1). This process could be used as it is in the BSCOR model. It is included as-is from the SCOR model (no adaptions are deemed necessary). It is once again important to highlight that the BSCOR model does not replace the SCOR model, it is a complement. The suppliers, upstream in the supply chain, uses the SCOR model as it is, except from the inclusion of the Builder's Deliver process. The contractor on the other hand uses the BSCOR model for mapping and measuring. As reported in Paper 4 (Thunberg et al. 2013), the processes bP6 - bP8 establish a plan based on the demand for material or resources depending on the process (bP6.1) and the supply of material or resources (bP6.2). The demand and supply are then balanced (bP6.3) and a company specific plan could be created (bP6.4). Figure 13 shows these activities for the sourcing plan but the procedure is also valid for the bP7. This is done for both contractor and subcontractors. All these plans are then coordinated (bP6.5) into a master plan (bP6.6) for the whole construction site, see Figure 14. All level 3 activities are also listed in Figure 15. The changes to bP7 and bP8 are not explicitly listed in Figure 15 as they are similar to the bP6 process.

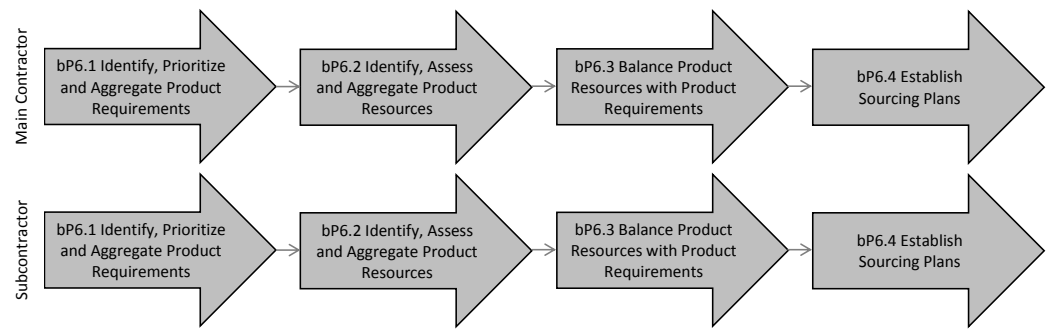

Figure 13 : Both the main- and the subcontractors develop their own plans first.

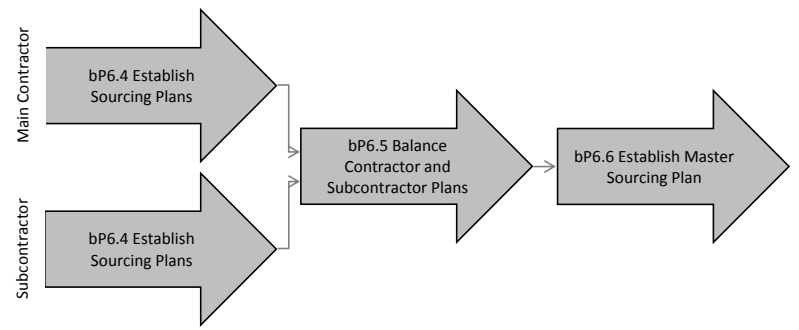

Figure 14 : The balancing of plans into one master plan. 


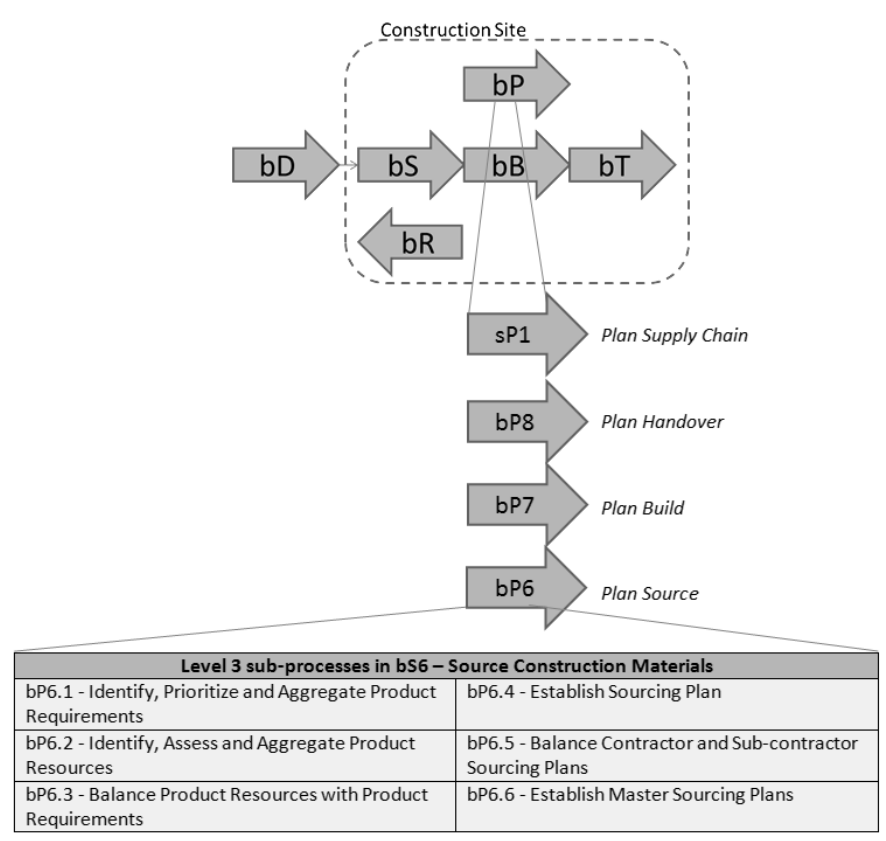

Figure 15 : All level 3 activities for the Plan Source process.

\subsubsection{The Deliver Process}

Considering the material flow in the BSCOR model, the scope starts at the suppliers and ends on the site. The delivery process in the BSCOR model consists of three level 2 processes: Deliver Make-to-Stock Materials (bD1), Deliver Make-to-Order Materials (bD2), and Deliver Engineer-to-Order Materials (bD3), see Figure 12. At the supplier, the Deliver process keeps the original division between Make-to-Stock, Make-to-Order, and Engineer-to-Order products as suggested by the SCOR model. Alterations are made in level 3 of these processes to better follow the suggested Builder's Source processes. For example, a level 3 activity concerning notifying incoming deliveries, or delayed, are added. The activity of installing the product is removed, as all materials are mounted/erected either by the main contractor or by any of the subcontractors. These changes together with the other level 3 activities are listed in Figure 16. These alterations are also implemented in the bD2 and bD3 processes, but are not explicitly demonstrated in Figure 16 as for the bD1. It is explicitly demonstrated in Figure 16 that the installation process (sD1.14) is removed, as this activity is performed in the Build Contractor (bB6) or the Build Subcontractor (bB8) processes. 


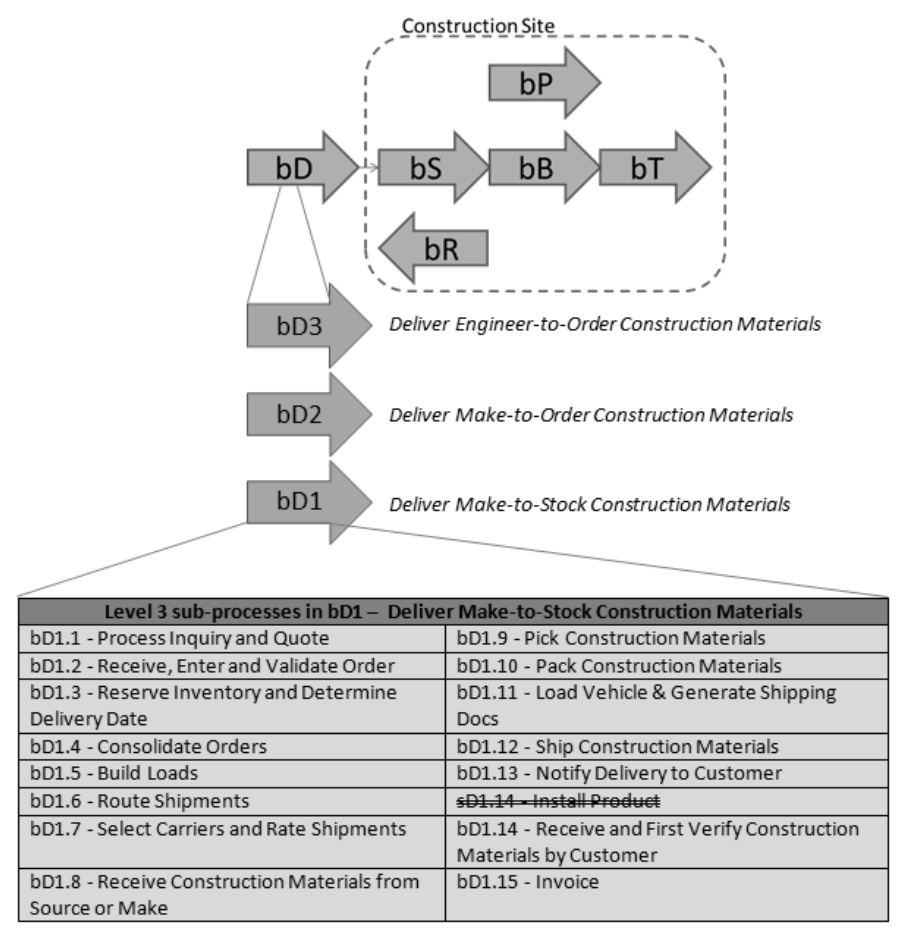

Figure 16 : All level 3 activities in the bD1 process.

\subsubsection{The Source Process}

The BSCOR model divides the Source processes in level 2 into three types based on the above mentioned principles, see Figure 12. The Source process in level 2 is therefore divided into Source Construction Materials (bS6) where the contractor source material, Source Construction Resources (bS7) where the contractor rent resources like cranes, scaffolding, and wheel loaders for shorter periods of time, and Source Sub-contractor (bS8) where subcontractors source their own materials, see Paper 2 (Persson and Thunberg 2012). Figure 17 depicts these level 2 processes plus the level 3 activities for the process of sourcing materials for the main contractor. These three different types of sourcing processes are seldom coordinated at the construction site. The division is made to clearly differentiate between these three types of processes and to make it possible to highlight the need for coordination.

The main alteration in level 3 regards the verification process. Materials are often not verified as extensively as in the manufacturing industry due to special terms of condition in the construction industry. The first verification process (bS6.5) is more of a visual inspection whereas the second one (bS6.8) concerns the full inspection after the packaging has been broken. These alterations are also implemented in the bS7 and bS8 processes, but are not explicitly demonstrated in Figure 17 as for the bS6. 


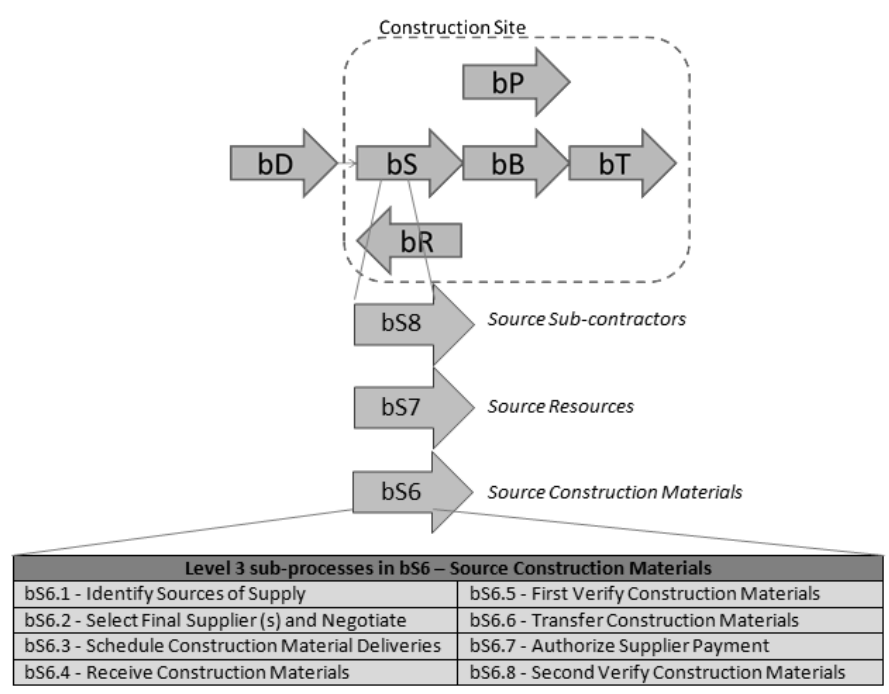

Figure 17 : All level 3 activities for the bP6 process.

\subsubsection{The Build Process}

The Builder's Build process is the actual process of erecting a building. Also here, the principle of dividing material usage by contractor and subcontractors is valid, see Figure 12. The Plan process has the same coordination problem and creates a master plan for the whole construction site. In the Build process at level 2 both Build Contractor (bB6) and Build Subcontractor (bB8) are using the material brought there from the Source process. The level 2 and 3 processes for the bB6 process are all listed in Figure 18. The bB8 process consists of the same set of level 2 and 3 processes but with the focus in their definition on the subcontractors rather than the main contractor. These alterations are also implemented in the bB8 process, but are not explicitly demonstrated in Figure 18 as for the bB6. All activities in level 3 are collected from the List of New Construction Processes from the Swedish Construction Federation for new houses (BI 1999). Unlike the SCOR model, the BSCOR model does not explicitly state the produce and test activities. These two (in the SCOR model level 3) activities are instead implicitly incorporated in the definition of each level 3 activity. This is done as all activities regard some form of production, an explicit production activity would be too generic. It is explicitly demonstrated in Figure 18 that the staging of the final product (sM3.6) is removed, as a building object is not 'staged' according to the SCOR model's definition. 


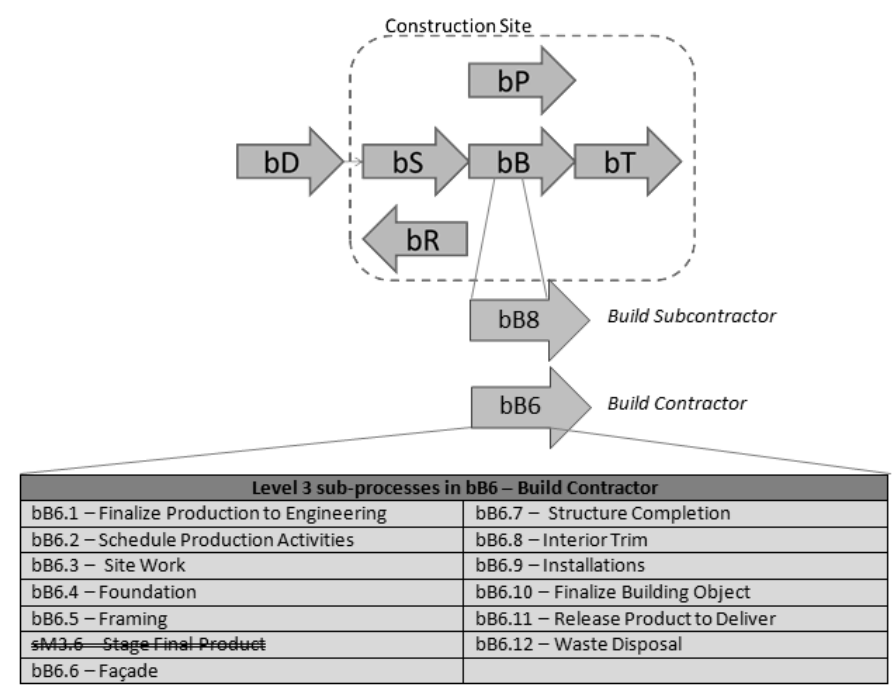

Figure 18 : All activities for the bB6 process.

\subsubsection{Metrics}

Two new metrics are suggested for keeping track of the construction logistics performance. These two are \% of Notify in time (bRL.2.5) and Number of movements of construction materials (bAM.1.4). The bRL.2.5 metric is a level 2 metric suggested as a part of the level 1 metric Perfect Order Fulfilment (sRL.1.1) while bAM.1.4 is a totally new level 1 metric. Perfect Order Fulfilment is a KPI that sets out to assess a supply chain's reliability (hence the prefix RL in the nomenclature). This metric controls performance in the Deliver process on the supplier side. In BSCOR, the new level 2 metric bRL.2.5 is incorporated in Perfect Order Fulfilment and measures if a shipment is notified in a proper manner or not. If a shipment is late and the site is unaware of the delay, resources for unloading are reserved for unnecessary amounts of time. The inclusion of this metric is a result from the perceived need from the construction industry that notification is of importance to avoid unnecessary costs.

While bRL. 2.5 concerns the Deliver process, the bAM.1.4 metric regards the Build process. Metrics in the Build process focuses on the logistics of the construction site. The contemporary literature reports on that many problems arise early in the supply chain and propagate to the construction site. A results of these problems could be that materials are often ordered well before they are used, leading to excessive storage times and storage levels. It prevents the craftsmen as the inventory areas are the same places as the production areas. That is why a new metric is introduced that measures the number of movements of construction materials at the site. Material should be unloaded on-site and transferred to its inventory-holding area and then moved to the place of use. All other movements, if the material is obstructing work or has a high risk of damage, are considered unnecessary. The bAM.1.4 metric is a KPI that has the purpose to assess assets management (AM). 


\subsection{Discussion on Implementation of the BSCOR Model}

The previously presented subsections introduced the reader to the changes to the SCOR model together with motivations to the alterations. The subsections presented processes and metrics that could be of use for mapping the logistics activities and measuring the supply chain performance in the construction industry. Section 3.3 The Supply Chain Operations Reference Model on the other hand offered an introduction to how the SCOR model can be used in order to identify problems and how to resolve them. These five phases are overall also applicable for the construction industry.

One issue to shed some light on, however, is who should lead the work with applying the BSCOR model. Yet another question is who should work with what in the framework? To bring some clarification on the former topic (who should lead the work) a recap to the literature review presented in section 2.2 Construction Supply Chain Management could be in place. Some argue that the client should take greater responsibility for implementing SCM principles/partnering (Dainty et al. 2001) while others promote the builders merchants (Vidalakis et al. 2011). However, Bygballe et al. (2010) argue that the main contractor should be responsible as they are positioned as a natural link between the converging chains in the network.

This discussion is also applicable on the BSCOR model: should the main contractor, the client, or yet another member (such as the builder's merchants) lead the work with implementing the BSCOR model? A likely candidate is the main contractor who, as Bygballe et al. (2010) point out, is situated as a converging point in most construction supply chains. This means the main contractor has first-hand information from the client but also the ability to reconcile different opinions and plans from the many sub-trades. In the end, this means the main contractor possess the best ability to map the flow and measure the overall supply chain performance.

The second issue mentioned above (who should work with what) regards which part of the company structure that should be responsible for what in the BSCOR model. The overall work with improvement project, presented in 3.3 The Supply Chain Operations Reference Model, should be led by head office staff. They have the possibility to collect information from all construction projects. With the collected information they can compare, develop best practices, and share the information to all other project. The work with mapping and measuring the daily work should on the other hand be performed by the managers on-site. They have first-hand information of what is going on and why. However, the information from on-site could first pass the regional office for keeping track on how the regional office 'is doing'. 


\section{Conclusions}

This section aims to present a general summary to show how each objective and the purpose have been fulfilled. This section also presents what the contributions are to both the academia and the construction industry. The thesis is summed-up with suggestions on future work.

\subsection{Fulfilment of the Research Objectives}

The four research objectives to fulfil within this study concerned what changes to the SCOR model that was deemed necessary: Objective 1-4. Adapt the SCOR model's Deliver, Source, Make, and Plan processes to the characteristics of the construction industry. Three of the papers $(2,3$, and 4$)$ contribute in fulfilling these objectives, together with section six in this thesis.

Paper 2 is the first paper that sets out to describe the necessary changes to the SCOR model. The focus in this paper is on the interface between construction material suppliers and the construction site. Therefore, suggested changes to the framework concern the processes Deliver and Source in the SCOR model, with corresponding metrics. Therefore it is considered that Objectives 1 and 2 are fulfilled in Paper 2. While Paper 2 focuses on the interface between the material suppliers and the construction site, Paper 3 focuses on the actual construction process (the Build process). Deemed changes therefore regards the process Make in the SCOR model. Paper 3 therefore aids in fulfilling Objective 3. Paper 4 on the other hand, takes the planning process in the SCOR model (called Plan) and scrutinises it to identify necessary changes. Thus, Paper 4 fulfils research Objective 4. Section 6. Developing a Construction Supply Chain Framework in this thesis takes the work of all three papers and compiles it into the final BSCOR model. The purpose with the study is therefore fulfilled in section 6 . The Table 10 below illustrates all changes done to the SCOR model.

The BSCOR model as such is presented in section 6 whereby the objective of developing a framework based on changes in the SCOR model can be seen as fulfilled. These changes are listed in Table 10. However, the BSCOR model should be seen as a continuously developing framework and documentation. Thus, all potential changes have probably not been detected. More changes are likely to be performed in the future as the development of the BSCOR model continues. 
Table 10 : The changes, adaptions, additions, and exclusions made to SCOR model to create the BSCOR model.

\begin{tabular}{|c|c|c|c|c|}
\hline & & Paper 2 & Paper 3 & Paper 4 \\
\hline \multirow{6}{*}{$\begin{array}{l}0 \\
\text { D } \\
0 \\
0 \\
0 \\
0 \\
0\end{array}$} & Level 1 & - & $\begin{array}{l}\text { Make process renamed } \\
\text { to Build (denoted } \mathrm{bB} \text { ) }\end{array}$ & - \\
\hline & Level 2 & $\begin{array}{l}\text { Change the Source } \\
\text { level } 2 \text { processes to } \\
\text { Source Construction } \\
\text { Materials (bS6), } \\
\text { Source Resources } \\
\text { (bS7), and Source } \\
\text { Subcontractors' } \\
\text { Materials (bS8) }\end{array}$ & $\begin{array}{l}\text { Added the two } \\
\text { processes Build } \\
\text { Contractors (bB6) and } \\
\text { Build Subcontractor } \\
\text { (bB8) }\end{array}$ & $\begin{array}{l}\text { Added the processes } \\
\text { Plan Build (bP7) and } \\
\text { Plan Handover (bP8) }\end{array}$ \\
\hline & Level 3 & $\begin{array}{l}\text { Added a second } \\
\text { verification activity in } \\
\text { the sourcing processes } \\
\text { (bS6.8) }\end{array}$ & $\begin{array}{l}\text { All level } 3 \text { processes } \\
\text { for Build are new and } \\
\text { are derived from (BI, } \\
1999)\end{array}$ & $\begin{array}{l}\text { Addition of the } \\
\text { Balance Sourcing } \\
\text { Plans activity (bS6.5) } \\
\text { and Establish Master } \\
\text { Sourcing Plans (bS6.6) }\end{array}$ \\
\hline & & $\begin{array}{l}\text { Revised the first } \\
\text { verification process } \\
\text { (bS6.5) }\end{array}$ & & \\
\hline & & $\begin{array}{l}\text { Addition of a notify } \\
\text { activity in the Deliver } \\
\text { process (bD1.13, } \\
\text { bD2.13 bD3.13) }\end{array}$ & & \\
\hline & & $\begin{array}{l}\text { Removed the } \\
\text { installation activity } \\
\text { (sD1.14, sD2.14, } \\
\text { sD3.14) }\end{array}$ & & \\
\hline \multirow{3}{*}{ 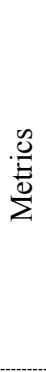 } & Level 1 & - & $\begin{array}{l}\text { Addition of a number } \\
\text { of movements metric } \\
\text { (bRL.1.4) }\end{array}$ & - \\
\hline & Level 2 & $\begin{array}{l}\text { Addition of a notify in } \\
\text { time metric in the } \\
\text { Perfect Order } \\
\text { Fulfilment (denoted } \\
\text { bRL.2.5) }\end{array}$ & - & - \\
\hline & Level 3 & - & - & - \\
\hline 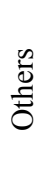 & & $\begin{array}{l}\text { Deliver to the } \\
\text { customer process } \\
\text { renamed to Handover } \\
\text { (denoted bH) }\end{array}$ & $\begin{array}{l}\text { Incorporate the } \\
\text { Produce and Test } \\
\text { activities in the level } 3 \\
\text { process definitions }\end{array}$ & $\begin{array}{l}\text { Identify that contractor } \\
\text { and subcontractors } \\
\text { should do their plans } \\
\text { by their own first and } \\
\text { balance them later on }\end{array}$ \\
\hline
\end{tabular}

The thesis also had an overall research objective: to present a logistical status in the construction industry. Of course it is impossible to draw conclusions about a whole 
industry from just three case studies. Yet, they do say something. For example in Paper 1 where the logistical performance is assessed. This is not done in other papers, so the results could be used for future comparison with other measurements. The practical research presented in Paper 1, 2, and 4, and the literature study presented in section 2 in this thesis also adds to the current knowledge about logistics in construction. It is difficult to say that this objective is 'fulfilled' but information presented in this thesis does contribute to fulfilling it.

In Paper 1, the supply chain performance is assessed through measuring the two metrics Perfect Order Fulfilment (POF) and Source Cycle Time (SCT) from the material suppliers to the construction site. The POF value could be used for future benchmarking purposes. The value of the SCT does indicate something about how much time is spent on the nonvalue adding activity of receiving materials. Paper 2 reveals the fact that no returns of construction materials are performed and that the sourcing process differs from the manufacturing industry (e.g. delivery of resources and separation of contractors' materials). Even when it comes to planning in construction it differs from the manufacturing industry, presented in Paper 4 and section 2. Paper 4 identifies a number of problems connected to planning in construction, presented in Table 1 in section 2.3.2 Planning in Construction. It is identified that (see section 2 and Paper 4) many of the problems stem from a lack of coordinating and synchronising works and plans among members in the supply chain. In section 2, these problems and other supply chain issues are described in more detail.

\subsection{Purpose Reflection and Contributions}

The purpose with this study was to develop a framework for process mapping and performance measurement in construction supply chains. Paper 2, 3, and 4 contribute in fulfilling this purpose. Each paper focuses on different aspects of the SCOR model while this thesis as such compiles the work from each paper. What can be questioned is whether the framework is 'fully' developed. The SCOR model as such is a continuously developing framework with the idea to always extend and refine it. This is also true for the BSCOR model; the work presented in this thesis could be seen as a starting point in developing the framework. It should also be noted that the title of this thesis is "Towards a framework for process mapping and performance measurement in construction supply chains". This indicates that the idea from the beginning was not to develop a complete framework. This thesis sets the foundation for continuously developing the BSCOR model.

From an academic perspective, this thesis contributes in filling the gap with a lack of frameworks for assessing construction supply chain performance from raw material producers to the end-customer. The BSCOR model, together with the SCOR model, does take this perspective. It also contributes on how the work with managing logistics activities is handled in the industry today. It therefore offers an ability to continue the work with identifying how coordination issues can be overcome etc. 
For practitioners, the main contribution is a framework for mapping logistic activities and assessing supply chain performance. In this manner, it is easier to recognise where improvement efforts should be dedicated. The results from fulfilling the overall objective, to present the logistic status in the construction industry, reveal that more focus has to be put on coordinating the work with planning. It also reveals that emphasis should be put on managing the relationship with the suppliers in order to decrease the number of faulty deliveries to the construction site. Another contribution is that this thesis reveals how much time is spent on non-value adding activities when receiving materials. This adds to the work performed by e.g. Josephson (1999), Love and Li (2000), Vrijhoef and Koskela (2000), and Frödell et al. (2008) about problems and non-value adding time in the supply chain.

\subsection{Discussion on Validity and Quality}

The work with developing the BSCOR model has not been problem free. First of all, the lack of systematic documentation on ordered materials and delivery-follow-ups inhibited the work on assessing supply chain performance in Paper 1. It was also difficult to determine on the unit for measuring performance. Should it be on parcel, order, or material level? In Paper 2, another type of problem was that no standardised routine was established on how to receive materials. This however also implies that the industry is in need of a standardised procedure for handling incoming deliveries. Otherwise new activities have to be 'invented' for every new delivery.

Another matter of concern to discuss is the degree of generalization. The measurement of POF and SCT cannot be said to represent the whole industry. The measurements are done at one construction site on about a dozen of different suppliers. To be able to draw general conclusions about the POF and SCT for the whole industry more measurements on several sites and suppliers have to be done. More studies on other construction companies are also necessary to be able to draw general conclusions about the proposed changes to the SCOR model. This has been done. Lohm Isberg and Olsson (2013) used the POF metric presented here on another construction company in Sweden. They concluded that POF for "inner wall material" (plasterboards, studs, etc.) were even lower than presented in Paper 1 in this thesis.

Of bigger concern for the soundness of the project is how validity and quality of the project have been ensured. The problem that violates the soundness is the use of master students for collecting data. Using less research-oriented students for collecting data in an exploratory research project has some obvious disadvantages for the project. If I as a researcher not exactly know what we are looking for (as in exploratory research projects) how should the students know? Students could be used to collect e.g. measurement if the 'phenomenon' is clearly identified and defined. As the students are leas research-oriented it could have affect validity and reliability. In research projects, validity and reliability are of outmost importance. This might result in temporary opinions or situations are elevated to facts, without further validation or verification. This has been avoided through clearly inscriptions to the students on how to verify data. It has also been avoided through testing 
the developed ideas on other projects with other students. Finally, a way to avoid any validation and reliability problems was to select students with high grades, as higher grades can signal higher motivation and academic maturity.

\subsection{Suggestions of Further Development of the BSCOR Model}

The first thing that is necessary to do is to test the BSCOR model. During the work with developing the framework, changes and experience from one case study is tested in the succeeding case. However, a case study where all suggested changes are tested and validated has not been performed. For example, the managers in all three cases in this study thought it was necessary to include the criterion of notifying in time in the perfect order fulfilment metric. Is this also valid for other cases and in other companies? This has to be further investigated.

Another topic concerning testing is to test if the framework actually does bring the anticipated benefits, lowering the costs and improving productivity. This type of testing is quite difficult as it also includes testing the SCOR model as such. A significant amount of case study objects that have similar (even identical) settings in all aspects have to be included. To find construction projects that are identical is difficult; the test will therefore be more of a quasi-experiment kind. Another issue is the prolonged time period for this type of quasi-experiment. A construction project often last for about one to two years. If a considerable amount of case study objects should be included, the testing project is likely to be of a prolonged nature. The test will therefore take a long time to realise and it is not certain if the results (to the advantage or disadvantage of the framework) depend on the merits of the BSCOR model or on contextual differences.

In the BSCOR model, something that needs to be further developed is the measurement part. As it is now, two metrics are added to the framework, but the rest of the metrics in the SCOR model are believed to suite the construction industry. However, an extensive examination of the metrics is necessary. Are there any metrics missing, should any of the SCOR metrics be revised, etc.? A great part of the BSCOR model today is devoted to the processes and not the metrics.

Finally, even if the BSCOR model is developed in this thesis, the question of how it should be used, and by whom, is not treated. Wherefore any upcoming study concerning BSCOR should analyse how it should be implemented. Also, the study should investigate who should lead the work with implementing the framework, and how it should be implemented by different companies in the chain. It is realised in this thesis that the suppliers could still use the SCOR model as it is, but how should the intersection between the two frameworks look like? I believe that a natural leader for implementing the BSCOR model is the main contractor, as it possesses a natural link between all members in the supply chain. However, it would be of interest to study whether the client is a better suited leader of implementation, especially for non-turnkey contracts. 
7. CONCLUSIONS

66 


\section{References}

Adams, C., and Neely, A., (2000). The Performance Prism to Boost M\&a Success. Measuring Business Excellence, 4 (3), 19.

Agapiou, A., Clausen, L.E., Flanagan, R., Norman, G., and Notman, D., (1998). The Role of Logistics in the Materials Flow Control Process. Construction Management \& Economics, 16 (2), 131-137.

Akintoye, A., McIntosh, G., and Fitzgerald, E., (2000). A Survey of Supply Chain Collaboration and Management in the Uk Construction Industry. European Journal of Purchasing \& Supply Management, 6 (3-4), 159-168.

Amornsawadwatana, S., (2011). Effective Design of the Construction Supply Chain: A Case of Small Buildings in Thailand. In: IEEE International Conference on Industrial Engineering and Engineering Management, 2011 Singapore. 206-210.

(APICS) The Association for Operations Management, (2013). Apics's Dictionary [Online]. Available: http://www.apics.org/dictionary/dictionaryinformation?ID=3984 [Accessed 27th of May 2013].

Arditi, D., Sikangwan, P., and Tokdemir, O.B., (2002). Scheduling System for High Rise Building Construction. Construction Management \& Economics, 20 (4), 353-364.

Atkinson, R., (1999). Project Management: Cost, Time and Quality, Two Best Guesses and a Phenomenon, Its Time to Accept Other Success Criteria. International Journal of Project Management, 17 (6), 337-342.

Bai, C., and Sarkis, J., (2012). Supply-Chain Performance-Measurement System Management Using Neighbourhood Rough Sets. International Journal of Production Research, 50 (9), 2484-2500.

Baladhandayutham, T., and Venkatesh, S., (2012). An Analysis on Application of Lean Supply Chain Concept for Construction Projects. Synergy (0973-8819), 10 (1), 2536.

Ballard, G., (2000). The Last Planner System of Production Control. Doctoral Thesis (Doctor of Philosophy). University of Birmingham.

Ballard, G., and Howell, G.A., (2003). An Update on Last Planner. In: IGLC11, 2003 Virginia USA. Group for lean construction.

Bankvall, L., Bygballe, L.E., Dubois, A., and Jahre, M., (2010). Interdependence in Supply Chains and Projects in Construction. Supply Chain Management: An International Journal, 15 (5), 385-393. 
Bassioni, H.A., Price, A.D.F., and Hassan, T.M., (2005). Building a Conceptual Framework for Measuring Business Performance in Construction: An Empirical Evaluation. Construction Management \& Economics, 23 (5), 495-507.

Bemelmans, J., Voordijk, H., Vos, B., and Buter, J., (2012). Assessing Buyer-Supplier Relationship Management: Multiple Case-Study in the Dutch Construction Industry. Journal of Construction Engineering \& Management, 138 (1), 163-176.

Bengtsson, J., and Gustad, Ö., (2008). Kartläggning Av Materialflödet I Peabs Försörjningskedja Till Byggarbetsplatsen, Med Scor. Master (Master). Linköpings universitet.

Bertelsen, S., and Nielsen, J. (1997). Just-in-Time Logistics in the Supply of Building Materials. 1st International Conference on Construction Industry Development: Building the future Together. Singapore.

(BI) The Swedish Construction Federation (1999). Nybyggnadslista [Online]. Available: http://publikationer.bygg.org/Userfiles/Info/518/Nybyggnadslistan_1999 110429. pdf [Accessed 25th of June 2012]

Bolstroff, P., and Rosenbaum, R., (2007). Supply Chain Excellence - a Handbook for Dramatic Improvement Using the Scor Model. 2nd. New York: Amacom.

Bresnen, M., and Marshall, N., (2000). Partnering in Construction: A Critical Review of Issues, Problems and Dilemmas. Construction Management \& Economics, 18 (2), 229-237.

Brewer, P.C., and Speh, T.W., (2000). Using the Balanced Scorecard to Measure Supply Chain Performance. Journal of Business Logistics, 21 (1), 75-93.

Business Dictionary, (2013). Businessdictionary.Com [Online]. Available: http://www.businessdictionary.com/definition/performance.html [Accessed 18th of October 2013].

Bygballe, L.E., Jahre, M., and Swärd, A., (2010). Partnering Relationships in Construction: A Literature Review. Journal of Purchasing \& Supply Management, 16 (4), 239-253.

Cameron, W.B., (1963). Informal Sociology: A Casual Introduction to Sociological Thinking. Random House.

Caplice, C., and Sheffi, Y., (1994). A Review and Evaluation of Logistics Metrics. The International Journal of Logistics Management, 5 (2), 11-28.

Caplice, C., and Sheffi, Y., (1995). A Rreview and Evaluation of Logistics Performane Measurement System. The International Journal of Logistics Management, 6 (1), $61-74$

Caron, F., Marchet, G., and Perego, A., (1998). Project Logistics: Integrating the Procurement and Construction Processes. International Journal of Project Management, 16 (5), 311-319. 
Chan, A.P.C., and Chan, A.P.L., (2004). Key Performance Indicators for Measuring Construction Success. Benchmarking: An International Journal, 11 (2), 203-221.

Cheng, J.C.P., Law, K.H., Bjornsson, H., Jones, A., and Sriram, R.D., (2010). Modeling and Monitoring of Construction Supply Chains. Advanced Engineering Informatics, 24 (4), 435-455.

Christopher, M., (2011). Logistics and Supply Chain Management. 4th. Edinburgh Gate: Prentice Hall - Financial Times.

Chua, D.K.H., and Kog, Y.C., (1999). Critical Success Factors for Different Project Objectives. Journal of Construction Engineering \& Management, 125 (3), 142.

Cohen, S., and Roussel, J., (2005). Strategic Supply Chain Management. New York: McGraw-Hill.

Cox, A., and Ireland, P., (2002). Managing Construction Supply Chains: The Common Sense Approach. Engineering Construction \& Architectural Management (Blackwell Publishing Limited), 9 (5/6), 409-418.

(CSCMP) Council of Supply Chain Management Professionals, (2013). Definition of Logistics Management [Online]. Available: http://cscmp.org/about-us/supplychain-management-definitions [Accessed 29th of May 2013].

Dainty, A.R.J., Briscoe, G.H., and Millett, S.J., (2001). Subcontractor Perspectives on Supply Chain Alliances. Construction Management \& Economics, 19 (8), 841848.

Dawood, N., (2010). Development of 4d-Based Performance Indicators in Construction Industry. Engineering, Construction \& Architectural Management, 17 (2), 210230.

di Martinelly, C., Riane, F., and Guinet, A., (2009). A Porter-Scor Modelling Approach for the Hospital Supply Chain. International Journal of Logistics Systems and Management, 5 (3), 436-456.

Dubois, A., and Gadde, L.-E., (2000). Supply Strategy and Network Effects Purchasing Behaviour in the Construction Industry. European Journal of Purchasing \& Supply Management, 6 (3-4), 207-215.

Dubois, A., and Gadde, L.-E., (2002). The Construction Industry as a Loosely Coupled System: Implications for Productivity and Innovation. Construction Management \& Economics, 20 (7), 621.

Egan, J., (1998). Rethinking Construction. Department of the Environment, Transport and the Regions. London

Eisenhardt, K.M., (1989). Building Theories from Case Study Research. Academy of Management Review, 14 (4), 532-550. 
Ellram, L.M., and Cooper, M.C., (1990). Supply Chain Management, Partnership, and the Shipper - Third Party Relationship. International Journal of Logistics Management, 1 (2), 1-10.

Eriksson, P.E., (2010). Partnering: What Is It, When Should It Be Used, and How Should It Be Implemented? Construction Management \& Economics, 28 (9), 905-917.

ESPRIT, (1993). Cimosa: Open System Archtecture for Cim. 2nd. New York: SpringerVerlag.

Faniran, O.O., and Love, P.E.D., (1999). Optimal Allocation of Construction Planning Resources. Journal of Construction Engineering \& Management, 125 (5), 311.

Farlex, (2013). The Free Dictionary [Online]. Available: http://www.thefreedictionary.com/mapping [Accessed 18th of October 2013].

Fawcett, S.E., and Cooper, M.B., (1998). Logistics Performance Measurement and Customer Success. Industrial Marketing Management, 27 (4), 341-357.

Fearne, A., and Fowler, N., (2006). Efficiency Versus Effectiveness in Construction Supply Chains: The Dangers of "Lean" Thinking in Isolation. Supply Chain Management: An International Journal, 11 (4), 283-287.

Fellows, R., (2009). Culture in Suplly Chains. In: S. Pryke, ed. Construction Supply Chain Management. Hong Kong: Wiley-Blackwell, 42-72.

Fernie, S., and Thorpe, A., (2007). Exploring Change in Construction: Supply Chain Management. Engineering, Construction \& Architectural Management, 14 (4), 319-333.

Fettke, P., Loos, P., and Zwicker, J., (2005). Business Process Reference Models: Survey and Classification. In: E. Kindler, \& M. Nüttgens, ed. Third International Conference on Business Process Management, 5th of Sep 2005 Nancy, France.

Fisher, M.L., (1997). What Is the Right Supply Chain for Your Product? Harvard Business Reveiw.

Frödell, M., Josephson, P.E., and Lindahl, G., (2008). Swedish Construction Clients' Views on Project Success and Measuring Performance. Journal of Engineering, Design and Technology, 6 (1), 21-32.

Gidado, K., (2004). Enhancing the Prime Contractor's Pre-Construction Planning. Journal of Construction Research, 5 (1), 87-106.

González, V., Alarcón, L.F., Maturana, S., Mundaca, F., and Bustamante, J.A., (2009). Rational Commitment Model: Improving Planning Reliability and Project Performance. In: IGLC17, 2009 Taipei, Taiwan. 207-218.

Green, S.D., Fernie, S., and Weller, S., (2005). Making Sense of Supply Chain Management: A Comparative Study of Aerospace and Construction. Construction Management \& Economics, 23 (6), 579-593. 
Gunasekaran, A., Patel, C., and McGaughey, R.E., (2004). A Framework for Supply Chain Performance Measurement. International Journal of Production Economics, 87 (3), 333.

Gunasekaran, A., Patel, C., and Tirtiroglu, E., (2001). Performance Measures and Metrics in a Supply Chain Environment. International Journal of Operations \& Production Management, 21 (1/2), 71-87.

Gyllin, G., and Thunberg, M., (2010). Analysis of Scor Implementation at Peab. Masters (Masters). Linköping University.

Harland, C.M., (1996). Supply Chain Management: Relationships, Chains and Networks. British Journal of Management, 7), S63-S80.

Houlihan, J.B., (1985). International Supply Chain Management. International Journal of Physical Distribution and Materials Management, 15 (1), 22-38.

Hsu, L.-L., (2005). Scm System Effects on Performance for Interaction between Suppliers and Buyers. Industrial Management \& Data Systems, 105 (7), 857-875.

Jang, H., Russell, J.S., and Yi, J.S., (2003). A Project Manager's Level of Satisfaction in Construction Logistics. Canadian Journal of Civil Engineering, 30 (6), 11331142 .

Javalds, R., and Lokander, H., (2012). En Utvärdering Av Scor Modellens Tillämpbarhet Inom Byggbranschen. Master Thesis (Master Thesis). Linköping university.

Johansen, E., and Porter, G., (2003). An Experience of Introducing Last Planner into a Uk Construction Project. In: IGLC10, 22-24 July 2003 Virginia, USA. International Group for Lean Construction.

Johansen, E., and Wilson, B., (2006). Investigating First Planning in Construction. Construction Management \& Economics, 24 (12), 1305-1314.

Johansson, M., and Persson, F., (2011). Towards a Scor-Based Analysis Tool for Construction Management and Logistics. In: F. Persson, \& M. Rudberg, ed. PLANs FoT-konferens, 2011 Norrköping Sweden. Stockholm: PLAN, 125-139.

Johansson, R., (2012). Kartläggning Av Byggprocessen Hos Peab Med Hjälp Av Scor. Master (Master Thesis). Linköping university.

Josephson, P.-E., (2013). Produktivitetsläget I Svenskt Byggande 2013. SBUF. Göteborg

Josephson, P.-E., and Saukkoriipi, L., (2005). Slöseri I Byggprojekt, Behov Av Förändrat Synsätt. FoU-Väst.

Josephson, P.E., and Hammarlund, Y., (1999). The Causes and Costs of Defects in Construction: A Study of Seven Building Projects. Auto. in Const., 8 (6), 681-687.

Kagioglou, M., Cooper, R., and Aouad, G., (2001). Performance Management in Construction: A Conceptual Framework. Construction Management \& Economics, 19 (1), 85-95. 
Kaplan, R.S., and Norton, D.P., (1992). The Balanced Scorecard: Measures That Drive Performance. Harvard Business Reveiw, 1 (1), 71-79.

Karim, K., Marosszeky, M., and Davis, S., (2006). Managing Subcontractor Supply Chain for Quality in Construction. Engineering, Construction \& Architectural Management, 13 (1), 27-42.

Kelsey, J., Winch, G.M., and Penn, A., (2001). Understanding the Project Planning Process: Requirements Capture for the Virtual Construction Site. University College London. London

Kocaoğlu, B., Gülsün, B., and Tanyaş, M., (2011). A Scor Based Approach for Measuring a Benchmarkable Supply Chain Performance. Journal of Intelligent Manufacturing.

Koskela, L., (1992). Application of the New Production Philosophy to Construction. Thesis (PhD). Stanford University.

La Londe, B.J., and Masters, J.M., (1994). Emerging Logistics Strategies: Blueprints for the Next Century. International Journal of Physical Distribution \& Logistics Management, 24 (7), 35-47.

Lambert, D.M., and Cooper, M.C., (2000). Issues in Supply Chain Management. Industrial Marketing Management, 29 (1), 65-83.

Larson, P.D., and Halldorsson, A., (2004). Logistics Versus Supply Chain Management: An International Survey. International Journal of Logistics: Research \& Applications, 7 (1), 17-31.

Latham, M., (1994). Constructing the Team. HMSO. London

Laufer, A., (1991). Construction Planning in Uncertain Environments. International Journal of Project Management, 9 (1), 53-60.

Laufer, A., and Tucker, R.L., (1987). Is Construction Project Planning Really Doing Its Job? A Critical Examination of Focus, Role and Process. Constructiom Managementt \& Economics, 5 (3), 243-266.

Legnani, E., (2011). Controlling and Improving the Provision of after-Sales Services. Doctoral Thesis (Doctor of Philosophy). Universtà Degli Studi di Bergamo.

Ling, F.Y.Y., and Peh, S., (2005). Key Performance Indicators for Measuring Contractors' Performance. Architectural Science Review, 48 (4), 357-365.

Lohm Isberg, M., and Olsson, D., (2013). Analys Och Utvärdering Av Logistik Vid Byggandet Av Kvarteret Spinnrocken I Norrköping. (Bachelor). Linköping Univeristy.

Love, P., and Edwards, D., (2004). Forensic Project Management: The Underlying Causes of Rework in Construction Projects. Civil Engineering \& Environmental Systems, 21 (3), 207-228. 
Love, P.E.D., Irani, Z., and Edwards, D.J., (2004). A Seamless Supply Chain Management Model for Construction. Supply Chain Management, 9 (1), 43-56.

Love, P.E.D., and Li, H., (2000). Quantifying the Causes and Costs of Rework in Construction. Construction Management \& Economics, 18 (4), 479-490.

Lönngren, H.-M., Rosenkranz, C., and Kolbe, H., (2010). Aggregated Construction Supply Chains: Success Factors in Implementation of Strategic Partnerships. Supply Chain Management: An International Journal, 15 (5), 404-411.

Mainul Islam, M.D., and Faniran, O.O., (2005). Structural Equation Model of Project Planning Effectiveness. Construction Management \& Economics, 23 (2), 215-223.

Menches, C.L., Hanna, A.S., Nordheim, E.V., and Russell, J.S., (2008). Impact of PreConstruction Planning and Project Characteristics on Performance in the Us Electrical Construction Industry. Construction Management \& Economics, 26 (8), 855-869.

Meng, X., (2012). The Effect of Relationship Management on Project Performance in Construction. International Journal of Project Management, 30 (2), 188-198.

Mentzer, J.T., DeWitt, W., Keebler, J.S., Soonhoong, M., Nix, N.W., Smith, C.D., and Zacharia, Z.G., (2001). Defining Supply Chain Management. Journal of Business Logistics, 22 (2), 1-25.

Mentzer, J.T., Stank, T.P., and Esper, T.L., (2008). Supply Chain Management and Its Relationship to Logistics, Marketing, Production, and Operations Management. Journal of Business Logistics, 29 (1), 31-46.

Modig, N., (2007). Material Flows Incurred by Activities at Project Sites. Doctoral Thesis (Doctor of Philosophy). Chalmers University of Technology.

Mohamed, A.N., (2001). Knowledge Based Approach for Productivity Adjusted Construction Schedule. Expert Systems with Applications, 21 (2), 87-97.

Najmi, M., Etebari, M., and Emami, S., (2012). A Framework to Review Performance Prism. International Journal of Operations \& Production Management, 32 (10), 1124-1146.

Nordqvist, S., (2008). Analys Av Logistikflöden Hos Inwall, Katrineholm. Linköpings universitet.

O'Brien, W.J., London, K., and Vrijhoef, R., (2002). Construction Supply Chain Modeling: A Research Review and Interdisciplinary Research Agenda. In: IGLC10, 2002 Gramado, Brazil. 129-148.

Pan, N.H., Lin, Y.Y., and Pan, N.F., (2010). Enhancing Construction Project Supply Chains and Performance Evaluation Methods: A Case Study of a Bridge Construction Project. Canadian Journal of Civil Engineering, 37 (8), 1094-1106. 
Patel, P.C., Azadegan, A., and Ellram, L.M., (2013). The Effects of Strategic and Structural Supply Chain Orientation on Operational and Customer-Focused Performance. Decision Sciences, 44 (4), 713-753.

Persson, F., and Thunberg, M., (2012). Adapting the Scor Model to the Construction Industry Settings. In: J. Töyli, et al., ed. 24th NOFOMA 2012, 7-8th of June 2012 Turku, Finland.

Pheng, L.S., and Chuan, Q.T., (2006). Environmental Factors and Work Performance of Project Managers in the Construction Industry. International Journal of Project Management, 24 (1), 24-37.

(PMI) Project Management Institute, (2013). Project Definition [Online]. Available: http://www.pmi.org/ [Accessed 09 Sep 2013].

Power, D., (2005). Supply Chain Management Integration and Implementation: A Literature Review. Supply Chain Management, 10 (4), 252-263.

Quayle, M., (2003). A Study of Supply Chain Management Practice in Uk Industrial Smes. Supply Chain Management: An International Journal, 8 (1), 79-86.

Radujković, M., Vukomanović, M., and Dunović, I.B., (2010). Application of Key Performance Indicators in South-Eastern European Construction. Journal of Civil Engineering and Management, 16 (4), 521-530.

Saad, M., Jones, M., and James, P., (2002). A Review of the Progress Towards the Adoption of Supply Chain Management (Scm) Relationships in Construction. European Journal of Purchasing \& Supply Management, 8 (3), 173-183.

(SCB) Statistics Sweden, (2013). Available: www.scb.se [Accessed 9th of May 2013].

(SCC) Supply Chain Council, (2013). Supply Chain Council's Homepage [Online]. Available: http://www.supply-chain.org [Accessed 21st of March 2013].

Scheer, A.-W., (2000). Aris - Business Modeling. 3rd. New York: Springer.

Shin, H., Collier, D.A., and Wilson, D.D., (2000). Supply Management Orientation and Supplier/Buyer Performance. Journal of Operations Management, 18 (3), 317333.

Soekov, E., and Lill, I., (2011). Effect of Subcontracting on Construction Scheduling. In: $I C-S S S E-D C^{\prime} 11,27-29$ th of May 2011 Lanzarote, Spain. 105-110.

Son, J., and Rojas, E.M., (2011). Evolution of Collaboration in Temporary Project Teams: An Agent-Based Modeling and Simulation Approach. Journal of Construction Engineering \& Management, 137 (8), 619-628.

Song, H.-S., and Lind, H., (2012). Dålig Produktivitetsutveckling I Byggindustrin: Ett Faktum Eller Ett Mätfel. KTH. Stockholm 
Stefansson, G., and Russell, D.M., (2008). Supply Chain Interfaces: Defining Attributes and Attribute Values for Collaborative Logistics Management. Journal of Business Logistics, 29 (1), 347-359.

Stevens, G., (1986). Integrating the Supply Chain. International Journal of Physical Distribution and Materials Management, 19 (8), 3-8.

Surie, C., and Wagner, M., (2008). Supply Chain Analysis. In: H. Stadtler, \& C. Kilger, (eds.) Supply Chain Management and Advance Planning - Concepts, Models, Software and Case Studies. 4th. New York: Springer, 37-64.

Tennant, S., and Fernie, S., (2013). Organizational Learning in Construction Supply Chains. Engineering, Construction \& Architectural Management, 20 (1), 83-98.

Thakkar, J.J., (2012). Scm Based Performance Measurement System: A Preliminary Conceptualization. Decision (0304-0941), 39 (3), 5-43.

Thunberg, M., (2011). Performance Measurements for Improving Construction Logistics - a Case Study. In: F. Persson, \& M. Rudberg, ed. PLANs FoT-konferens, 2011 Norrköping. Stockholm: PLAN, 109-123.

Thunberg, M., and Persson, F., (2012). Adapting the Scor Make Process to the Construction Industry Settings [online]. Available from: www.bscor.com [Accessed 3rd of Aprile, 2013].

Thunberg, M., and Persson, F., (2013a). A Logistics Framework for Improving Construction Supply Chain Performance. In: S.D. Smith, \& D.D. Ahiaga-Dagbui, ed. Procs 29th Annual ARCOM Conference, 2-4 September 2013a Reading, UK. Association of Researchers in Construction Management, 545-555.

Thunberg, M., and Persson, F., (2013b). Using the Scor Model's Performance Measurements to Improve Construction Logistics. Production Planning and Control.

Thunberg, M., Persson, F., and Rudberg, M., (2013). Coordinated Supply Chain Planning in Construction. In: O.J. Klakegg, et al., ed. 7th Nordic Consference on Construction Economics and Organisation, 12-14th of June 20132013 Trondheim, Norway. Construction Researchers on Economics and Organisation in the Nordic region (CREON) \& Akademika Publishing, 2013, 546-556.

Toor, S.-u.-R., and Ogunlana, S.O., (2010). Beyond the 'Iron Triangle': Stakeholder Perception of Key Performance Indicators (Kpis) for Large-Scale Public Sector Development Projects. International Journal of Project Management, 28 (3), 228236.

Wegelius-Lehtonen, T., (2001). Performance Measurement in Construction Logistics. International Journal of Production Economics, 69), 107-116.

Wegelius-Lehtonen, T., and Pahkala, S., (1998). Developing Material Delivery Processes in Cooperation: An Application Example of the Construction Industry. International Journal of Production Economics, 56/57 (3), 689-698. 
Verdouw, C.N., Wolfert, J., Beulens, A.J.M., and Trienekens, J.H., (2010). Process Modelling in Demand-Driven Supply Chains: A Reference Model for the Fruit Industry. Computers and Electronics in Agriculture, 73 (2), 174-187.

Vickery, S.K., Jayaram, J., Droge, C., and Calantone, R., (2003). The Effects of an Integrative Supply Chain Strategy on Customer Service and Financial Performance: An Analysis of Direct Versus Indirect Relationships. Journal of Operations Management, 21 (5), 523.

Wickramatillake, C.D., Koh, S.C.L., Gunasekaran, A., and Arunachalam, S., (2007). Measuring Performance within the Supply Chain of a Large Scale Project. Supply Chain Management: An International Journal, 12 (1), 52-59.

Vidalakis, C., Tookey, J.E., and Sommerville, J., (2011). The Logistics of Construction Supply Chains: The Builders' Merchant Perspective. Engineering Construction \& Architectural Management, 18 (1), 66-81.

Voordijk, H., (2010). Physical Distribution Costs in Construction Supply Chains: A Systems Approach. International Journal of Logistics Systems and Management, 7 (4), 456-471.

Voss, C., Tsikriktsis, N., and Frohlich, M., (2002). Case Research in Operations Management. International Journal of Operations \& Production Management, 22 (2), 195-219.

Vrijhoef, R., and Koskela, L., (2000). The Four Roles of Supply Chain Management in Construction. European Journal of Purchasing \& Supply Management, 6), 169178.

Yeung, J.F.Y., Chan, A.P.C., and Chan, D.W.M., (2008). Establishing Quantitative Indicators for Measuring the Partnering Performance of Construction Projects in Hong Kong. Construction Management \& Economics, 26 (3), 277-301.

Yin, K.R., (2009). Case Study Research: Design and Methods. 4th. London: Sage.

Yu, H.T., Tweed, T., Al-Hussein, M., and Nasseri, R., (2009). Development of Lean Model for House Construction Using Value Stream Mapping. Journal of Construction Engineering \& Management, 135 (8), 782-790. 


\section{Thesis Outline}

The articles associated with this thesis have been removed for copyright reasons. For more details about these see:

http://urn.kb.se/resolve?urn=urn:nbn:se:liu:diva-101964 